\title{
Adaptation des animaux d'élevage aux multiples contraintes des régions chaudes
}

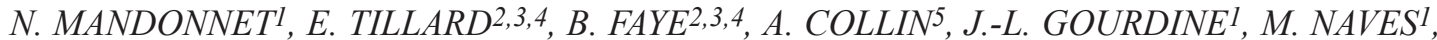 \\ D. BASTIANELLI $I^{2,3,4}$, M. TIXIER-BOICHARD ${ }^{6,7}$, D. RENAUDEAU ${ }^{1}$ \\ ${ }^{1}$ INRA, UR0143 Unité de Recherches Zootechniques, Domaine Duclos Prise d'eau, F-97170 Petit-Bourg, Guadeloupe \\ 2 INRA, UMR0868 Systèmes d'Elevage Méditerranéens et Tropicaux, 2 place Viala, F-34060 Montpellier, France \\ ${ }^{3}$ CIRAD, Systèmes d'Elevage Méditerranéens et Tropicaux, Campus International de Baillarguet, \\ F-34398 Montpellier, France \\ ${ }^{4}$ Supagro, Systèmes d'Elevage Méditerranéens et Tropicaux, 2 place Viala, F-34060 Montpellier, France \\ IINRA, UR83 Recherches Avicoles, F-37380 Nouzilly, France \\ ${ }^{6}$ INRA, UMR1313 Génétique Animale et Biologie Intégrative, F-78352 Jouy-en-Josas, France \\ ${ }^{7}$ AgroParisTech, Génétique Animale et Biologie Intégrative, 16 rue Claude Bernard, F-75231 Paris, France \\ Courriel : Nathalie.Mandonnet@antilles.inra.fr ; emmanuel.tillard@cirad.fr
}

En régions chaudes, la pérennité des systèmes d'élevage repose sur la capacité d'adaptation des cheptels à de multiples contraintes climatiques et biotiques. La compréhension des mécanismes physiologiques et génétiques d'adaptation est un défi majeur pour la communauté scientifique et le secteur de l'élevage. Les populations animales tropicales constituent des modèles de choix pour l'étude des processus adaptatifs et les connaissances acquises seront valorisées en régions chaudes mais pourront également être remobilisées en zone tempérée, notamment du fait du contexte actuel de changement climatique.

Les recherches sur l'élevage en zone tempérée, et par mimétisme en zone tropicale, ont longtemps été guidées par l'amélioration de la productivité sous l'angle du progrès technique, et de critères économiques comme la marge brute ou le revenu. Désormais, les changements climatiques qui affectent ou vont affecter de plus en plus les zones tempérées, la fréquence grandissante de crises sanitaires ou financières graves et la volatilité des prix (produits, intrants) au niveau mondial nécessitent d'accorder une importance grandissante à la capacité d'adaptation des systèmes d'élevage à un environnement physique, politique, culturel, social et économique changeant (Dedieu et Ingrand 2010) quelle que soit la zone climatique.

En zones chaudes (méditerranéenne, désertique, tropicale et subtropicale), les contraintes environnementales sont d'abord climatiques : températures et taux d'humidité élevés, et/ou précipitations irrégulières. Il en découle, suivant les zones géographiques, des disponibilités en aliments ou en eau variables en quantité et en qualité, ainsi qu'une grande variété de maladies (notamment parasitaires). L'adaptation en élevage est un terme très général qui décrit la faculté d'un animal à faire face aux contraintes de l'environnement, en mobilisant ses grandes fonctions physiologiques. L'objectif du processus adaptatif pour l'animal est de maintenir son bien-être et de garantir sa survie (homéostase) et celle de sa descendance (homéorhèse).

L'objet de cet article est de faire l'état des connaissances sur les composantes de l'adaptation (comportement, physiologie, génétique...) et sur la manière de les mettre à profit pour optimiser la productivité et la résilience des systèmes d'élevage tropicaux, c'est-à-dire leur aptitude à faire face à des perturbations plus ou moins importantes du milieu.

\section{1 / Les composantes de l'adaptation}

\section{1 / Adaptation aux effets directs du climat tropical}

La répartition géographique mondiale des animaux d'élevage témoigne de leur aptitude à supporter des conditions climatiques extrêmes, notamment les températures élevées et l'humidité ou les sècheresses drastiques observées sous les latitudes tropicales et subtropicales. Cependant, le stress thermique reste une contrainte majeure pour le bien-être et la productivité animale en région chaude (Kadzere et al 2002) pour laquelle les différentes espèces ont mis en place des mécanismes d'adaptation.

a) Grands principes de la thermorégulation et de son contrôle

La thermorégulation est la fonction physiologique qui permet de maintenir la température interne dans des limites physiologiques étroites (homéothermie). Cette fonction contrôle l'équilibre entre la production de chaleur et les pertes de chaleur. La production de chaleur d'un animal est un sous-produit de son métabolisme. Les pertes de chaleur sont effectuées selon deux voies principales, la voie sensible et la voie latente. Les pertes sensibles peuvent s'effectuer selon trois modalités physiques (radiation, conduction ou convection), tandis que les pertes de chaleur par voie latente s'effectuent par évaporation au 
Figure 1. Représentation schématique des relations entre température ambiante (Ta) et température corporelle (TC).

Représentation schématique des relations entre Température ambiante (Ta) et Température corporelle (Tc)

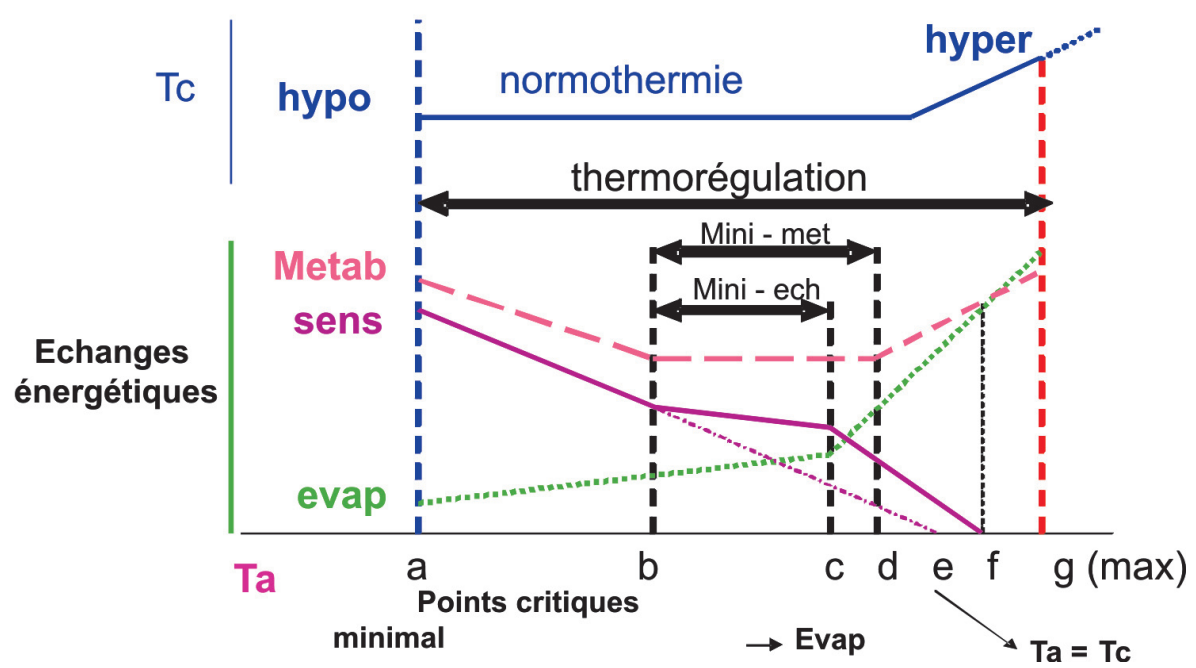

Mini-met $=$ zone de métabolisme minima $;$ Mini-ech $:$ zone du moindre effort de thermorégulation ; point $\mathbf{a}$ : température minimale critique ; point $\mathbf{b}$ : température critique ; point $\mathbf{c}$ : température à partir de laquelle commencent les pertes de chaleur par évaporation; point $\mathbf{d}$ : température critique maximale ; point e : égalité entre température corporelle et température ambiante ; point $\mathbf{f}$ : les pertes sensibles sont nulles car la production de chaleur métabolique est égale aux pertes par évaporation ; point $\mathbf{g}$ : maximum thermique ; Metab : production de chaleur métabolique ; sens : pertes de chaleur par voie sensible ; evap : pertes par évaporation.

niveau cutané (transpiration) ou au niveau respiratoire (perspiration).

La figure 1 montre l'évolution de la température corporelle et des échanges d'énergie en fonction de la température ambiante (Ta) chez les homéothermes (Mount et al 1974). Lorsque la température ambiante augmente au-delà de la zone de thermoneutralité (la zone entre $\mathrm{b}$ et $\mathrm{d}$ ), les mécanismes de régulation (réduction de thermogenèse/augmentation de thermolyse) sont saturés et l'animal ne parvient plus à maintenir sa température interne constante. A partir d'un certain seuil, les fonctions du cerveau s'altèrent entraînant un coma et la mort (Silanikove 2000). Dans la zone de confort thermique (température comprise entre $b$ et $c$ ), l'homéothermie est maintenue grâce à des mécanismes peu coûteux en énergie (comportement plus calme ; pertes sensibles). Au-delà de cette zone, les pertes de chaleur par la voie sensible diminuent et l'homéothermie est assurée uniquement par une augmentation importante des pertes par évaporation. En réalité, ces réponses varient en fonction de la durée d'acclimatation à la chaleur (Renaudeau et al 2010).

Au fil de l'évolution et de la sélection naturelle, certaines espèces ou populations ont déplacé leur zone de confort en développant des particularités anatomiques facilitant les pertes de chaleur. Les besoins physiologiques des animaux influencent également cette zone de confort thermique. Ainsi, elle varie en fonction des espèces et des races au sein des espèces, du sexe, de l'âge, du niveau de production et du stade physiologique. D'autres facteurs de milieu, comme l'humidité relative et la vitesse de l'air, interviennent aussi, notamment quand sont en jeu des pertes de chaleur par évaporation.

\section{b) Chez les monogastriques}

Grâce à leur mode d'élevage à forte densité et leur faible aptitude à perdre de la chaleur par évaporation (absence de glandes sudoripares fonctionelles), les monogastriques sont particulièrement sensibles à la chaleur.

Sur le plan anatomique, le poids corporel, la composition corporelle, le tégument et les phanères (plumage et appendices non emplumés des volailles) influencent l'adaptation à la chaleur.

Le poids corporel et le format sont des facteurs de régulation des échanges thermiques. Les animaux plus petits sont en général moins sensibles à la chaleur car ils présentent un meilleur rapport surface/volume, qui facilite l'évacuation de la chaleur corporelle par voie sensible (Dauncey et Ingram 1986). De manière générale, les animaux à croissance lente sont moins sensibles à la chaleur que ceux à croissance rapide, en relation avec une plus faible production de chaleur métabolique (Sandercock et al 2006). Cet effet s'explique chez le porc par une réduction des besoins d'entretien et du coût énergétique du dépôt corporel (rapport dépôt protéique/dépôt de lipides) (Noblet et al 1999). Chez le poulet de chair, un rapport surface/volume plus élevé pour les femelles peut expliquer leur meilleure thermotolérance pendant la phase de croissance (Cahaner et Leenstra 1992). Cependant, un effet inverse, en faveur des mâles, est observé chez des poulets à croissance lente de type label (N'Dri et al 2007). Lorsque les animaux sont exposés à un challenge thermique chronique, des changements morphologiques interviennent et se traduisent, notamment chez le porc, par des carcasses plus longilignes (augmentation du rapport surface/poids) (Rinaldo et al 1998). Enfin, la longueur des extrémités telles que les tarses, la crête, les barbillons des volailles, les oreilles (partie du corps très vascularisée), la queue, les pattes et le groin des cochons augmente, ce qui contribue également à accroître les surfaces d'échange et à améliorer les pertes de chaleur (Dauncey et Ingram 1986). Une lignée de poules pondeuses, $\mathrm{R}+$, sélectionnée sur une forte consommation résiduelle présente un développement particulier de la crête, des barbillons et des tarses, qui facilitent l'évacuation de la chaleur induite par la thermogénèse alimentaire, et améliore sa thermotolérance (Bordas et Minvielle 1997).

Au-delà de leur zone de confort thermique, la variation de la composition corporelle des animaux peut être interprétée comme un mécanisme d'adaptation. La production de chaleur associée au dépôt protéique est généralement nettement plus élevée que celle associée au dépôt de lipides. En effet, les rendements énergétiques de la fixation d' $1 \mathrm{~g}$ de lipides et d'1g de protéines sont respectivement de 83 et $70 \%$. L'augmentation du dépôt lipidique au détriment des protéines sous l'effet direct de la chaleur peut donc être considérée comme une adaptation visant à réduire la production de chaleur métabolique. Chez les volailles, les animaux exposés à $32^{\circ} \mathrm{C}\left(v s 22^{\circ} \mathrm{C}\right)$ ont un dépôt protéique réduit de $54 \%$ en alimentation ad libitum et de $38 \%$ à même ingéré alimentaire (Ain Baziz et al 1996, Temim et al 2000). Cette diminution du dépôt protéique pourrait résulter à la fois d'une diminution de la capacité de synthèse protéique et de modifications des voies de signalisation post-récepteur de l'insuline (Boussaid-Om-Ezzine et al 2010). Chez le porc, l'effet direct de la 
température sur la répartition des dépôts tissulaires a été mis en évidence durant la phase de croissance (Le Bellego et al 2001) mais pas en post-sevrage (Collin et al 2001b) ce qui semble logique avec le fait que la sensibilité à la chaleur augmente avec le poids des animaux. Par ailleurs, dans la plupart des espèces, l'animal développe une réponse indirecte à la chaleur via une réduction spontanée de sa consommation alimentaire dont les effets s'apparentent à ceux d'une restriction alimentaire (amélioration de l'indice de consommation et carcasses moins grasses). Chez le porc, l'effet indirect de la température l'emporte sur l'effet direct car la majorité des travaux disponibles dans la bibliographie montrent que l'adiposité des carcasses diminue à température élevée $\left(29-30^{\circ} \mathrm{C}\right)$ (Renaudeau et Gourdine 2010). Au contraire, l'adiposité corporelle des poulets augmente au chaud (Geraert et al 1993).

Chez le porc, au-delà de $25^{\circ} \mathrm{C}$, la température modifie également la répartition des masses adipeuses avec une augmentation de la part relative du gras interne par rapport au gras externe. Cette modification des dépôts adipeux est liée à une réduction de l'activité des enzymes lipogéniques dans le gras externe et une augmentation de l'activité de la lipoprotéine lipase dans le gras interne (Rinaldo et al 1998). Ces mécanismes favorisant les pertes de chaleur par diminution de l'isolation thermique des animaux, il en résulte une meilleure thermotolérance.

Le pelage et le plumage des animaux agissent comme des isolants dans la mesure où ils retiennent une quantité plus ou moins importante d'air. Les qualités isolantes d'un pelage dépendent de la densité, de la longueur et de la structure des poils. A $35^{\circ} \mathrm{C}$, la pilosité des porcs est réduite par rapport à la thermoneutralité ce qui a pour conséquence de réduire ses propriétés isolantes (Dauncey et Ingram 1986). Le plumage est une composante essentielle des pertes de chaleur par voie sensible des volailles. Une réduction de $15 \%$ du plumage de poulets d'élevage est d'ailleurs observée lors de l'exposition à la chaleur $\left(25-32^{\circ} \mathrm{C}\right.$ et humidité relative de $65 \%$ ), comparativement à une situation de thermoneutralité $\left(21-25^{\circ} \mathrm{C}\right.$ et humidité relative de $73 \%$ ) (Lagana et al 2007). Le plumage varie aussi dans sa répartition, sa structure et sa densité sous l'effet de gènes à effets majeurs ou de la sélection qui modulent en conséquence la thermotolérance des volailles. Les mutations affectant le plumage tel que le gène cou nu NA (Mérat 1986) ou frisé $F$ (Zerjal et al 2010) améliorent la thermotolérance avec une meilleure survie et une meilleure productivité en conditions chaudes. La situation extrême consiste en l'absence totale de plumage avec la mutation Scaleless, récemment introduite dans une lignée à croissance rapide (Cahaner et al 2008). A l'opposé, les animaux porteurs de la mutation crête en pois $(P)$ ont une crête et des barbillons dont la taille est fortement diminuée ce qui réduit les pertes de chaleur par la crête, zone importante de déperditions de chaleur. La couleur du plumage peut affecter indirectement la thermotolérance par son effet sur l'absorption de chaleur par rayonnement, plus élevée pour les couleurs foncées, mais aussi par son effet sur la qualité de plumage, les plumages clairs étant moins détériorés (Mérat et al 1979).

Sur le plan comportemental, des réactions végétatives (impliquant le système nerveux autonome) vont permettre d'augmenter les pertes de chaleur et de limiter la production de chaleur. Elles concernent le comportement alimentaire, l'ingestion et l'activité physique.

Chez les volailles, les modifications de comportement alimentaire face à un stress thermique chronique se manifestent par une réduction de consommation d'aliment de $24 \%$ entre 22 et $32^{\circ} \mathrm{C}$ chez le poulet de chair entre 4 et 6 semaines d'âge (Geraert et al 1996). Cette baisse de la consommation ali- mentaire est curvilinéaire et est fortement corrélée à l'augmentation de la température interne (Picard et al 1993). Un degré d'augmentation de la température ambiante entre 30 et $35^{\circ} \mathrm{C}$ induit ainsi une réduction de consommation 4 fois plus importante que celle observée par degré d'augmentation entre 10 et $20^{\circ} \mathrm{C}$. La consommation alimentaire est plus importante en fin qu'en début de journée, même dans des conditions de température constante élevée (Picard 1989). La diminution de l'ingéré permet de limiter la thermogenèse alimentaire globale, même si la thermogenèse par $\mathrm{g}$ d'aliment ingéré est plus élevée à 32 qu'à $22^{\circ} \mathrm{C}$ (Geraert et al 1996). Les races locales, telles que la poule Fayoumi, conservent généralement un appétit élevé même lorsqu'elles reçoivent un aliment complet (Mérat et al 1983) et maintiennent davantage leur niveau d'ingestion en conditions chaudes (Mérat et Bordas 1982). Le même phénomène est observé avec la lignée $\mathrm{R}+$ sélectionnée sur une forte consommation alimentaire résiduelle (Bordas et Minvielle 1997). La consommation d'eau augmente au chaud, en liaison avec les pertes respiratoires accrues par l'hyperventilation (Borges et al 2004).

La chaleur modifie également de manière importante le comportement alimentaire des porcs. La moindre consommation alimentaire observée à

Photo 1. Poulet de 12 semaines de génotype sans plumes, homozygote pour l'allèle récessif sc (scaleless; Azoulay et al 2011), aux côtés de son frère hétérozygote $(+/ s c)$ normalement emplumé. Ces deux animaux sont issus du croisement d'une femelle $+/ s c$ et d'un mâle sc/sc.

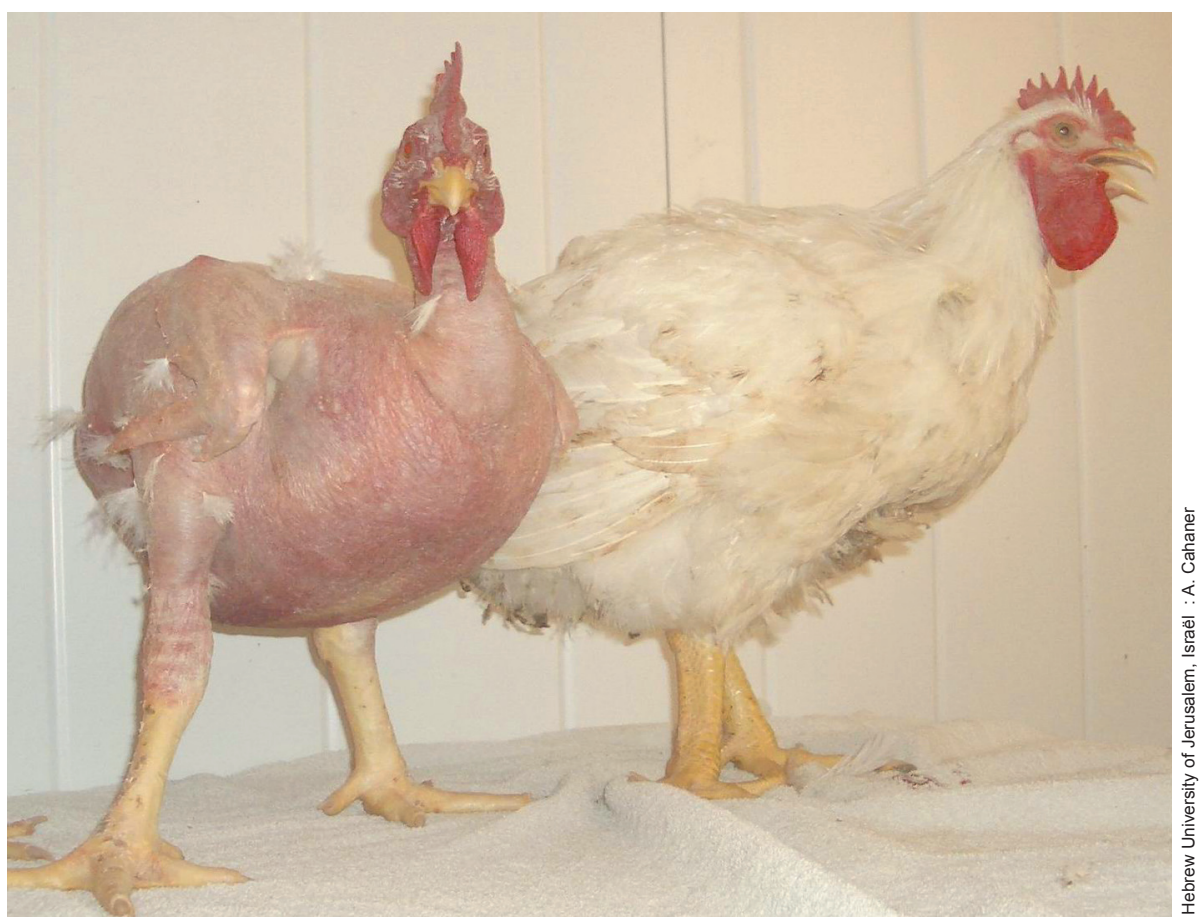


températures élevées se caractérise, dans un premier temps, par une diminution de la taille des repas alors que leur fréquence n'est pas modifiée (Collin et al 2001c). Cependant, chez les truies allaitantes, l'accroissement de l'intensité du stress thermique semble également provoquer une réduction du nombre de repas (Quiniou et al 2000b). Par ailleurs, les effets de la chaleur sur le comportement alimentaire des porcs semblent varier en fonction du stade d'acclimatation et du mode de logement (individuel $v s$ en groupe) (Renaudeau et al non publié). En pratique, la température n'est pas constante dans les élevages et varie au cours de la journée. Les porcs comme les poulets peuvent adapter leur comportement alimentaire pour compenser leur moindre consommation en période chaude par une ingestion d'aliment accrue pendant les périodes fraîches de la journée (Renaudeau et al 2006). Cette compensation dépend de la moyenne et de l'amplitude de la variation journalière de la température ambiante (Quiniou et al 2000a) du stade physiologique et de la race (Renaudeau et al 2005).

Pour augmenter les pertes de chaleur par voie sensible (conduction, convection, rayonnement) et limiter la production de chaleur les monogastriques modifient leur activité physique. Chez le porc, ces ajustements sont très nets avec un éparpillement du groupe où chaque individu adopte une posture qui lui permet d'optimiser la surface de contact entre l'animal et le sol et de minimiser le contact avec ses congénères (Xin 1999). Cette diminution de l'activité physique pourrait limiter la production de chaleur qui lui est associée. Cependant, chez le porcelet, celleci n'est pas significativement réduite, la diminution du temps passé en station «debout» étant vraisemblablement contrebalancée par le travail musculaire imposé par l'hyperventilation respiratoire (Collin et al 2001b). Des mécanismes de thermolyse insensibles peuvent également avoir une origine comportementale si le porc a accès à une mare ou à un bassin d'eau. Dans ce cas, la perte d'énergie liée à l'évaporation de boue ou d'eau à la surface du corps va être très efficace pour améliorer les pertes de chaleur. Chez les volailles, on observe le déploiement des ailes et l'étalement sur le sol pour augmenter la surface d'échange sur les régions les moins emplumées. Des modifications physiologiques favorisant la vasodilatation et l'augmentation du flux sanguin vers les organes périphériques amplifient ces pertes de chaleur (Wolfenson 1986). Au chaud, les oiseaux limitent les mouvements volontaires et notamment les déplacements (Deaton 1983, Yahav et al 2004b) normalement observés en condi- tions non stressantes (Gregorio Rosales 1994).

Sur le plan physiologique, en l'absence de sudation (glandes sudoripares absentes ou non fonctionnelles) ou en raison de l'emplumement, les pertes de chaleur par voies latente ou évaporative chez les monogastriques reposent sur l'hyperventilation respiratoire (Tesseraud et Temim 1999). Chez les volailles, ce processus consiste en une augmentation de la fréquence respiratoire - au prix d'une diminution du volume inspiré - le nombre d'inspirations par minute pouvant tripler entre 22 et $32^{\circ} \mathrm{C}$ (Leterrier et al 2009). Une conséquence potentiellement négative de l'hyperventilation prolongée est la baisse excessive du $\mathrm{CO}_{2}$ dans le sang, entraînant une perturbation de l'équilibre acidobasique du sang (alcalose respiratoire) qui limite notamment la fixation du calcium pour la synthèse de la coquille. Ce phénomène est principalement observé dans les phases de stress thermique aigu, et semble plus marqué chez le poulet que chez la dinde (Arad et Marder 1983, Comito et al 2007). Chez le porc, le rythme respiratoire augmente également à températures élevées mais, contrairement à la volaille, n'a pas ou peu de conséquences sur l'équilibre acido-basique du sang. En accord avec les modifications observées chez la poule (Wolfenson et al 1978) des ajustements cardiovasculaires sont rapportés chez le porc (Collin et al 2001a). Ils se caractérisent par une augmentation du flux sanguin au niveau sous-cutané et au niveau du système respiratoire et une

\section{Photo 2. Dromadaire femelle blanc et son petit.}

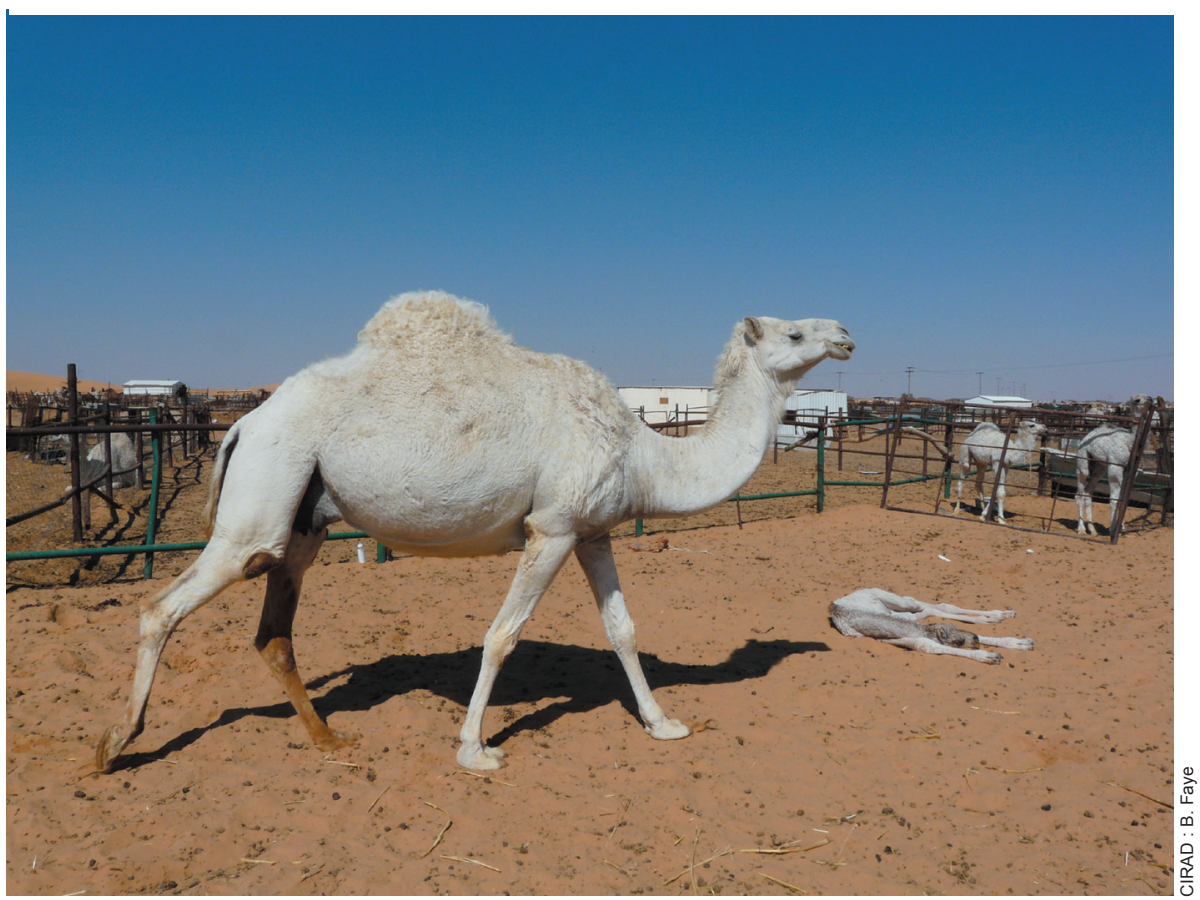

diminution du flux vers les tissus fortement producteurs de chaleur (foie, muscles, tube digestif). La vasodilatation des artérioles sous-cutanées augmente la quantité de chaleur transférée de l'intérieur de l'organisme à la peau, et en modifiant ainsi la température cutanée, améliore les pertes de chaleur par radiation et convection. Ces ajustements cardio-vasculaires sont sous le contrôle du système nerveux autonome. nants

Sur le plan anatomique, les populations homéothermes de ruminants présentes en régions chaudes ont tendance à être de plus petit format que celles des régions tempérées. Comme pour les monogastriques, l'amélioration du rapport surface/poids vif chez les animaux de petite taille leur permet de dissiper la chaleur plus efficacement (Silanikove 2000). C'est dans les régions chaudes d'Afrique que l'on rencontre les populations naines, notamment caprines et bovines (Epstein 1971).

Le dromadaire, quant à lui, a développé une aptitude particulière grâce à la présence d'une bosse qui concentre les réserves adipeuses (plus de 90\% des réserves adipeuses de l'animal, Faye et al 2002). Elle assure un rôle dans la thermorégulation en limitant leur répartition sous la peau et donc en facilitant la dissipation cutanée de la chaleur. Par ailleurs, lorsque le sol est chaud et que l'animal se tient debout, ses longs membres isolent la masse corporelle des

\section{c) Chez les ruminants et pseudorumi-}


calories dégagées par le terrain. Même en position baraquée, le coussinet sternal maintient l'abdomen légèrement audessus du sol, permettant ainsi une circulation d'air favorisant la dissipation de la chaleur. La qualité de la robe joue également un rôle non négligeable, par sa couleur claire d'abord, par sa texture ensuite. La peau est recouverte d'une toison épaisse en hiver, qui tombe d'elle-même en été. Cette toison de laine constitue un excellent isolant qui crée un gradient de température de la surface de la peau à l'extrémité des fibres de laine, réduisant ainsi les pertes hydriques cutanées. Enfin, le dromadaire possède une peau épaisse, protectrice, munie d'un système de glandes sudoripares bien réparties sur l'ensemble du corps, qui ne s'active que lorsque la température corporelle dépasse $42^{\circ} \mathrm{C}$, c'est-à-dire lorsque la capacité de stockage calorifique est dépassée.

Chez les bovins, les différences anatomiques entre taurins (Bos taurus) et zébus (Bos indicus) traduisent aussi des différences d'adaptation : les replis de peau particulièrement développés sous l'abdomen des zébus (fanon et prépuce) permettent d'augmenter la surface d'échange. Les oreilles et la bosse sont des sites privilégiés pour la thermorégulation grâce à une peau plus fine, des couches de papilles plus fines également chez des bovins Gir (Bhayani et Vyas 1990). Enfin comme chez le chameau, la bosse concentre des réserves adipeuses. Par ailleurs, Ferreira et al (2009) ont montré que l'épaisseur du pelage, la disposition et l'activité des glandes sudoripares étaient responsables du meilleur contrôle de l'homéostasie chez des bovins croisés Holstein $\times$ Gir que chez des Holstein purs.

Sur le plan comportemental, la durée d'ingestion et la durée des déplacements sont des variables d'ajustement de la régulation thermique des ruminants. En effet, chez des bovins croisés Limousin $\times$ Créole moyennement affectés par la chaleur, Naves (2003) décrit une durée d'ingestion quotidienne une demi-heure plus longue que chez les Créole (soit $+27 \%$ ) pour couvrir des besoins d'entretien et de production plus importants de $21 \%$. Coulon (1984a), au contraire, chez des bovins croisés Charolais $\times$ bovin local $\mathrm{du}$ Vanuatu, plus sensibles à la chaleur, observe des réductions d'appétit et de déplacements. Par ailleurs, les bovins Créole de Guadeloupe s'adaptent aux conditions climatiques plus contraignantes de la saison chaude en diminuant leur temps de rumination, en se reposant plus ou en se déplaçant moins au pâturage, en augmentant le temps d'ingestion nocturne à l'auge (Naves 2003). La production de chaleur interne est ainsi limitée (Wilson 1998). Ces comportements sont décrits de manière assez universelle, mais interviennent de manière plus ou moins marquée suivant les génotypes. Ils sont souvent rapportés chez des génotypes sensibles à la chaleur (Salas et al 1990, Langbein et Nichelmann 1993, Hammond et Olson 1994).

Aux heures chaudes, le dromadaire quant à lui, se tient préférentiellement face au soleil afin d'exposer la plus faible surface possible au rayonnement solaire maximal. Lorsqu'il est au pâturage, il choisit préférentiellement de brouter les fourrages ligneux plutôt que les graminées dès lors que la température externe augmente : cela lui permet de s'alimenter tout en restant à l'ombre des arbres. A l'inverse, en début et en fin de journée, il consommera de préférence les couverts herbacés.

Sur le plan physiologique, la régulation thermique fait intervenir différents mécanismes chez les ruminants. Chez la plupart des espèces, l'augmentation de la température externe conduit à l'augmentation du métabolisme général par effet de débordement des mécanismes classiques de régulation de la température interne. Ainsi, chez les vaches laitières hautes productrices élevées en zones tropicales, des températures et taux d'humidité élevés entraînent une diminution de la survie des gamètes, une diminution du taux de fécondation, et une diminution de la survie de l'embryon au cours des deux premières semaines de gestation (Gauthier et Thimonier 1985, Berbigier 1988, Putney et al 1989). Les températures élevées diminuent également l'ingestion, augmentent le déficit énergétique et entraînent, par cette voie métabolique indirecte, un effet négatif sur le niveau de production (Cavestany et al 1985, Berbigier 1988). Sous le climat tropical humide, les bovins Créole supportent des températures plus élevées que les animaux croisés avant de mettre en action des mécanismes de régulation (ventilation, transpiration...) car ils sont plus efficaces dans la régulation de leur température interne qui ne varie pas avec la saison (Naves 2003). Chez des bovins croisés au contraire, l'élévation de la température rectale est proportionnelle à l'humidité mesurée aux heures les plus chaudes de la journée. La variation du taux d'humidité relative suivant la saison serait ainsi un facteur déterminant de l'inconfort thermique, ce qui peut s'expliquer par une moindre efficacité des voies sensibles lorsque l'atmosphère ambiante est plus chargée en humidité (Berbigier 1988).

Enfin, une autre voie de régulation physiologique est la variation de la température interne au cours de la journée, notamment la faculté à baisser la température interne aux heures fraîches, phénomène qui traduit une meilleure thermolabilité. Berbigier (1988) et Brosh et al (1998) citent ce phénomène comme une stratégie physiologique d'adaptation à la chaleur, économe en eau, déjà observée chez le bovin Créole et dans l'espèce Bos Indicus, et plus encore chez le chameau (notamment l'espèce Camelus dromedarius). Lorsque la température ambiante décroît, notamment pendant la nuit, la température interne du dromadaire peut descendre à $34^{\circ} \mathrm{C}$. Durant les heures les plus chaudes, la température rectale peut atteindre $42^{\circ} \mathrm{C}$ sans que l'on puisse parler de fièvre. De tels écarts de température corporelle sont mortels pour la plupart des mammifères. Ces processus de refroidissement corporel, non seulement contribuent à économiser l'énergie nécessaire au maintien de la température interne, mais de plus s'effectuent sans consommation supplémentaire d'eau contrairement aux autres mammifères. Il a été mesuré qu'une augmentation de $6^{\circ} \mathrm{C}$ de la température corporelle chez un dromadaire pesant environ $600 \mathrm{~kg}$ lui permettait d'économiser 5 litres d'eau (Yagil 1985).

Dans la régulation thermique du dromadaire, le sang joue également un rôle primordial, en particulier lors de déshydratation. Son sang, à l'inverse de celui de la plupart des espèces, reste fluide ce qui lui permet de maintenir sa fonction de transfert de chaleur de la périphérie (plus fraîche du fait de l'évaporation) au cour. Enfin, chez le dromadaire, l'augmentation de la température interne s'accompagne d'une diminution de la consommation d'oxygène, indicateur d'une diminution générale du métabolisme. Autrement dit, le dromadaire est capable de déprimer la production de chaleur interne lorsqu'il est en contact avec les rayons du soleil aux heures les plus chaudes de la journée. Dans cette espèce comme chez les homéothermes de manière générale, la chaleur et la déshydratation dépriment l'activité thyroïdienne ralentissant ainsi le métabolisme général, notamment en lien avec l'augmentation de la sécrétion de bromure par la glande thyroïde dont l'effet «tranquillisant» est bien connu (Etzion et al 1987).

\section{d) Bases génétiques de la thermo-} tolérance

Comprendre les bases génétiques de l'adaptation des races aux environnements physique et climatique est aujourd'hui une question essentielle, en zone tempérée comme en zone tropicale. Chez le poulet, de nombreuses mutations qui ont un effet sur l'efficacité des échanges thermiques des animaux $(D W$, 
$N A, K, F \ldots)$ ont été mises en évidence. L'amélioration génétique devrait permettre d'obtenir à long terme, une plus grande efficacité thermorégulatrice, même s'il reste difficile de prévoir quelles seront les conséquences d'une telle évolution sur les potentiels de production. Les travaux sur la sélection de porcs résistants à la chaleur sont récents (Gourdine et al 2006). Les premiers résultats indiquent qu'il est possible de sélectionner des animaux avec de bonnes aptitudes à produire sous la contrainte thermique. Chez la truie allaitante, une importante variabilité sur la température rectale a été estimée avec une héritabilité modérée $\left(\mathrm{h}^{2}=0,25-0,30\right.$, Gourdine et al 2007). Chez le porc à l'engraissement, des travaux (Zumbach et al 2008) montrent que l'héritabilité du poids de carcasse est plus élevée en condition de stress thermique suggérant que l'effet de la chaleur doit être pris en considération dans l'objectif de sélection. Chez les bovins, de nombreux travaux australiens (Burrow 2006) montrent qu'il existe de la variabilité génétique sur différents critères liés à l'adaptation à la chaleur comme la température rectale ou l'importance du pelage. Par ailleurs, des travaux australiens ont été menés sur la détection de marqueurs SNP associés à la sensibilité de la production laitière des vaches à la chaleur (Hayes et al 2009). Un panel de SNP a été validé, permettant de contribuer à la sélection de vaches laitières thermotolérantes, c'est-à-dire par exemple d'animaux productifs et peu sensibles à une augmentation du THI (Temperature-Humidity Index) (Ravagnolo et al 2000).
Selon les espèces et les populations, des combinaisons de caractères anatomiques (le tégument et les phanères, le poids corporel et la composition corporelle), comportementaux et physiologiques permettent d'assurer au mieux l'homéothermie en cas de stress thermique. Les régions tropicales et subtropicales recèlent à ce titre des ressources génétiques animales adaptées.

\section{2 / Adaptation à la sous- alimentation et à la restriction hydrique}

En zones difficiles, la pérennité des systèmes d'élevage repose sur la capacité des animaux à survivre et à se reproduire en situation de forte contrainte alimentaire (élevages pastoraux en régions arides). La résilience des systèmes d'élevage repose en partie sur les potentiels adaptatifs des animaux à la sous-alimentation et sur l'efficacité des régulations comportementales et physiologiques impliquées dans la réponse adaptative (Blanc et al 2004).

\section{a) Composante comportementale}

- Types morpho-physiologiques et capacité à sélectionner la ressource alimentaire. Chez les ruminants, le processus évolutif a abouti au développement de capacités physiologiques digestives en rapport avec leur écologie alimentaire. Trois types morphophysiologiques ont été proposés pour classer les 150 espèces de ruminants selon des adaptations graduelles d'ordre anatomique (capacité des comparti- ments du tractus digestif, surface d'échange), physiologique (flore ruminale, production d'acide chlorhydrique, digestion des fibres et des tannins) ou comportemental (sélectivité) (figure 2, Hofmann 1989) :

- le type «sélecteur-concentrateur» rassemble des espèces de ruminants (plus de $40 \%$ des 150 espèces de ruminants inventoriées) adaptés à la digestion de végétaux facilement assimilables (feuille, fruit, graine), riches en constituants solubles; les espèces de ce type présentent une capacité sélective élevée leur permettant de se constituer un régime de très haute qualité nutritionnelle; on y trouve exclusivement des espèces de ruminants sauvages comme l'élan, les koudous «kudu», la girafe, etc. ;

- le type «brouteur» rassemble des espèces de ruminants $(25 \%)$ qui sont adaptés exclusivement à la digestion de l'herbe et des végétaux fibreux, riches en constituants pariétaux (cellulose) ; on y trouve la plupart des espèces de ruminants domestiques (bovin, ovin, buffle) ainsi que des espèces sauvages comme les cobs «buck», les gnous, les oryx, etc. D'un point de vue évolutif, le système digestif des brouteurs est «plus jeune» que le système digestif des animaux «sélectionneurs», ce qui démontrerait que l'adaptation à l'environnement végétal est un processus continu;

- un troisième type «intermédiaire ou opportuniste» rassemble des espèces $(35 \%)$ capables d'ajuster rapidement leur niveau métabolique (niveau d'ingestion) à des fluctuations saisonnières marquées du disponible fourrager (en

Figure 2. Types d'alimentation morpho-physiologiques observés chez les ruminants (Hofmann 1989).

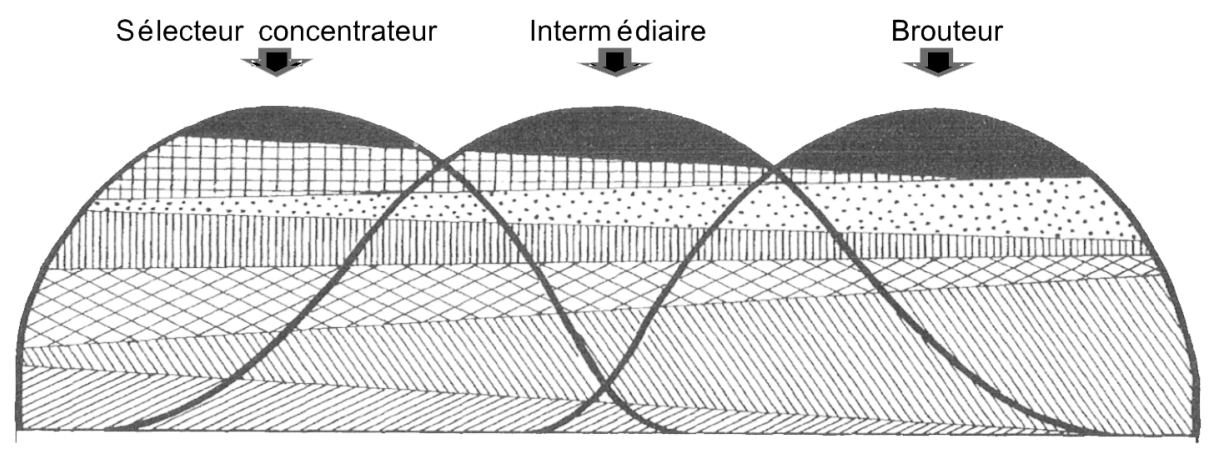

Capacités d'adaptation des ruminants

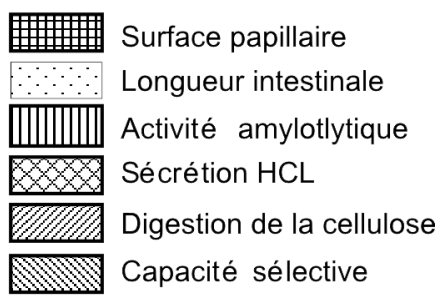

D'après Hoffman, 1989

Suni, Gerenuk, Cariacou, Dikkik, Chevreuil, Elan

Caribou, Chamois, Bouquetin, Wapiti, Pronghorn, Impala, Ch èvre, Sika

Topi , Gnou, Oryx, Oribi, «buck», Mouton Bovin, Bison, Buffle 
quantité et en qualité) et ainsi synchroniser un niveau de production élevé (lactation, constitution de réserves) avec la saison la plus favorable; on trouve dans ce groupe beaucoup d'espèces sauvages, la plupart des espèces d'antilopes africaines et deux espèces domestiques, les caprins et le cerf Elaphe.

L'élément clé de l'adaptation alimentaire est la capacité sélective (Hofmann 1989). Elle permet aux ruminants d'exploiter des ressources hétérogènes et d'élaborer un régime de meilleure valeur nutritionnelle que celui qui leur est globalement offert. Des travaux basés sur des modèles de simulation de digestion ruminale ont montré que la subsistance des ruminants de petite taille était conditionnée par l'ingestion d'un fourrage de qualité et que leur capacité sélective leur permettait de compenser leur faible capacité digestive (volume ruminal limité, transit ruminal élevé) (Demment et Van Soest 1985).

Les chèvres (groupe intermédiaire) ont développé des adaptations morphophysiologiques (posture bipédique, mobilité de la lèvre supérieure, conformation de l'arcade incisive) qui leur permettent de trier les portions les moins lignifiées des plantes, et de brouter des feuilles d'arbres épineux, comme les acacias, situées en hauteur $(1,5-2 \mathrm{~m})$ et ainsi de valoriser les ressources naturelles non utilisées par les autres ruminants domestiques (feuilles, fruits, graines...) (Landau et al 2000). Des observations similaires ont été effectuées chez le dromadaire. Faye et Tisserand (1989) ont montré que cette espèce donnait la préférence aux fourrages verts plutôt qu'aux fourrages secs aussi longtemps et aussi souvent qu'il le peut. En saison sèche, le dromadaire recherche les formations ligneuses encore vertes plutôt que les pailles du tapis herbacé. En revanche, en saison des pluies, il donne la préférence aux graminées vertes en phase végétative, riches en sel et/ou azote et augmente son niveau d'ingestion journalier (environ 2 à $3 \mathrm{~kg}$ bruts de fourrage par heure, contre 1 à $1,5 \mathrm{~kg}$ en saison sèche) (Faye et Tisserand 1989).

- Interactions animal-ressources. Les interactions entre animal et ressources sont encore mal connues en régions chaudes. En zone tropicale, les animaux parcourent d'assez longues distances quotidiennement, sur une ressource disponible qualitativement pauvre et s'amenuisant avec l'avancée de la saison sèche. Face à la pénurie et à la dispersion des ressources dans les milieux désertiques, le dromadaire dispose d'une double stratégie comportementale : i) il pratique un pâturage ambulatoire, c'est-à-dire qu'il ne cesse de brouter en marchant, ce qui peut le conduire à parcourir d'importantes distances au cours d'une journée que les bergers cherchent à limiter par des liens de contention; ii) il utilise une gamme de fourrages disponibles bien plus importante que les autres espèces (Rutagwenda et al 1989). Cette qualité est d'autant plus efficace que, à cause de sa résistance à la privation d'eau, le dromadaire peut s'éloigner considérablement des points d'eau et ainsi, valoriser des espaces non utilisés par d'autres espèces. Ceci permet ainsi de limiter le surpâturage autour des points d'abreuvement, phénomène bien connu dans les zones d'élevage bovin. Sur les parcours méditerranéens, les chèvres développent également un comportement opportuniste leur permettant de tirer profit de l'hétérogénéité des ressources (feuillage, herbes). A l'échelle d'une journée, cet opportunisme se traduit par une aptitude à adapter leur comportement alimentaire aux disponibilités locales, alternant des phases d'ingestion massive de fourrages grossiers et des phases de sélection d'aliment plus riches, plus rares, et parfois moins accessibles (épineux) durant lesquelles la préhensibilité devient un facteur limitant la vitesse d'ingestion (Meuret 1997). Au cours d'un circuit journalier de pâturage, l'animal alterne ainsi des phases d'alimentation où la masse linéaire ingérée est élevée (gramme de fourrage/mètre linéaire de déplacement) et des phases de recherche et de diversification du repas. Ces différents ajustements permettent aux animaux de limiter les variations $\mathrm{du}$ rapport feuilles/tiges et de maintenir constant le niveau d'ingestion et de couverture énergétique, en dépit des fluctuations de la ressource. En cas de sous-alimentation marquée, le zébu montre un accroissement de la vitesse d'ingestion, du poids de la bouchée et du temps passé à mastiquer une même quantité d'aliment sans qu'il y ait modification de la taille des particules présentes dans le rumen (Newman et al 1994, Grimaud et al 1999). Des résultats similaires ont été observés chez des vaches à haut potentiel élevées en zone tempérée (Delagarde et al 2008). Au pâturage, les ruminants compensent une diminution de la disponibilité alimentaire des couverts herbacés et maintiennent leur niveau d'ingestion en augmentant la fréquence de préhension et leur temps de pâturage (Blanc et al 2010).

\section{b) Composante physiologique}

Différents aspects de l'adaptation à la sous-alimentation peuvent être envisagés : le niveau et la réduction du métabolisme, l'efficience digestive, la valorisation de fourrages grossiers, la mobilisation des réserves corporelles, le recyclage des nutriments et la valorisation efficiente de l'eau (Alexandre et Mandonnet 2005).

- Niveau des besoins métaboliques. Le nanisme est généralement considéré comme une adaptation aux climats secs et chauds, en relation avec la règle de Bergman (Silanikove 2000) qui stipule que chez les homéothermes, les races sont de plus petit format en régions chaudes, en relation avec des besoins d'entretien plus faibles. Néanmoins, cette règle est à nuancer dans la mesure où les espèces de taille réduite sont très souvent élevées dans des environnements fortement contraints, où à la productivité et la qualité des fourrages sont limitées (Silanikove 2000).

Certains génotypes de petite taille que l'on trouve en région désertique ou subdésertique montrent des adaptations particulières. Comme d'autres races de petits ruminants, la chèvre Bédouine présente une aptitude particulière à digérer des fourrages de qualité médiocre, riches en fibres. Ses besoins énergétiques (en $\mathrm{kJ}$ par kg de poids métabolique et par jour) sont inférieurs aux estimations tirées de leur poids métabolique et inférieurs de $36 \%$ par rapport à ceux d'animaux de race européenne comme la Saanen ou la race Alpine (Silanikove 2000). La chèvre Bédouine est par ailleurs capable de stabiliser son poids corporel avec une quantité d'énergie ingérée inférieure de $50 \%$ à la quantité ingérée volontairement alors que le seuil observé chez les chèvres Saanen ne descend pas en dessous de 20-30\% (Silanikove 2000). On retrouve une aptitude similaire chez les zébus d'Afrique, exposés régulièrement à des longues périodes de déficit nutritionnel.

- Efficience digestive. Chez les ruminants, la baisse du niveau d'ingestion d'une même ration entraîne généralement une augmentation de la digestibilité de la matière organique, qui s'explique par un transit plus lent des particules de fourrages dans le tractus digestif et un temps de contact des aliments avec les microorganismes du rumen accru (Michalet-Doreau 1997, Doreau et al 2000). Il semble cependant que la relation entre baisse d'ingestion et augmentation de la digestibilité observée à des niveaux d'ingestion supérieurs à l'entretien ne puisse être transposée à des niveaux inférieurs à l'entretien. En effet, des essais menés en Afrique de l'Ouest sur des zébus (Grimaud et al 1999) et en Tunisie sur des brebis (Atti et al 2002) ont montré une baisse de digestibilité de 17 et $28 \%$ chez des animaux recevant une ration couvrant respectivement 33 et $20 \%$ des besoins énergétiques d'entretien. Dans les deux cas, la baisse de digestibilité a 
Tableau 1. Ecarts de digestibilité entre les espèces de ruminant désertiques et les espèces domestiques.

\begin{tabular}{|l|l|c|l|}
\hline \multicolumn{1}{|c|}{$\begin{array}{c}\text { Indicateur } \\
\text { de digestibilité }\end{array}$} & \multicolumn{1}{c|}{ Espèces } & $\%$ & \multicolumn{1}{c|}{ Références } \\
\hline $\begin{array}{l}\text { Digestibilité } \\
\text { de la } \mathrm{MO}^{1}\end{array}$ & $\begin{array}{l}\text { dromadaire - mouton } \\
\text { lama - mouton }\end{array}$ & $\begin{array}{l}56,2-52,4 \\
58,4-54,3\end{array}$ & Jouany 2000 \\
\hline $\begin{array}{l}\text { Digestibilité } \\
\text { de la } \mathrm{MS}^{1}\end{array}$ & chèvre Bédouine - Saanen & $68-61$ & $\begin{array}{l}\text { Silanikove } \\
\text { et al 1993 }\end{array}$ \\
\hline
\end{tabular}

${ }^{1} \mathrm{MO}$ : Matière organique ; MS : Matière sèche.

été associée à une diminution de la population des protozoaires du rumen et une augmentation du temps de rétention des particules dans le tractus digestif. Ces éléments soulèvent une question : est-ce l'allongement ou la réduction du temps de rétention des particules dans le tube digestif qui constitue un trait d'adaptation? La réponse n'est pas obligatoirement tranchée et doit prendre en compte les mécanismes morphophysiologiques sous-jacents : volume ruminal, longueur intestinale, surface papillaire, sélectivité et complexité des adaptations mises en œuvre (digestion des fourrages améliorée par un allongement du temps de rétention des particules alimentaires et recyclage de l'eau favorisé par un raccourcissement du temps de rétention des fluides) (Hummel et al 2008).

Chez les caprins, mais également les autres espèces de ruminants, l'ingestion de fourrages de mauvaise qualité entraîne une augmentation du temps de rétention digestif des particules (Tisserand et al 1991). Plusieurs études comparées ont montré que les espèces de ruminants désertiques ou subdésertiques (camélidés, addax, chèvres indigènes des zones désertiques) ont une meilleure capacité à digérer les fourrages pauvres que les ruminants domestiques (tableau 1). Cette supériorité s'explique par un temps de rétention supérieur des particules solides $(41 \mathrm{~h}$ chez la chèvre désertique contre $32 \mathrm{~h}$ en moyenne chez la Saanen) et des fluides dans les pré-estomacs (Tisserand et al 1991, Silanikove et al 1993, Jouany 2000) et une capacité à dégrader partiellement la lignine (Silanikove 2000).

- Mobilisation des réserves corporelles et croissance compensatrice. L'aptitude des ruminants à mobiliser leurs réserves corporelles en période de sous-alimentation et à les reconstituer rapidement lorsque les disponibilités alimentaires s'améliorent est le résultat d'un long processus évolutif. Lors d'une sous-alimentation, les adaptations physiologiques passent par la mise en œuvre de régulations destinées à maintenir l'équilibre physiologique interne de l'animal afin d'assurer sa survie dans un environnement donné (régulations homéostasiques). Elles comportent 3 étapes successives : $i$ ) une mobilisation coordonnée et séquentielle de substrats endogènes tels que ceux stockés dans les réserves corporelles, ii) la mise en place de mécanismes d'épargne des métabolites limitants (glucose, acides aminés) et iii) une diminution du métabolisme de base et des dépenses énergétiques (déplacements, mouvements) (Blanc et al 2004). Ces régulations ont un déterminisme environnemental et génétique (capacité d'ajustement homéostasique) (Sauvant 1994 Grimard et al 2002). Houdijk et al (2001) estiment à $2,5 \mathrm{~g} / \mathrm{kg}$ de poids vif la quantité de protéines mobilisables par le mouton via ses réserves corporelles.

De manière générale, deux situations peuvent être distinguées : le cas d'une sous-alimentation relative où l'ingestion est limitante et ne permet pas de couvrir les besoins (c'est le cas de la vache laitière en début de lactation), et

Figure 3. Stratégies d'alimentation de brebis barbarines placées en situation de forte sous-alimentation (- $20 \%$ lot $M$ ), très forte sous alimentation (- $40 \%$ lot B) ou alimentation stabilisée (lot témoin) (Atti et Bocquier 1999).

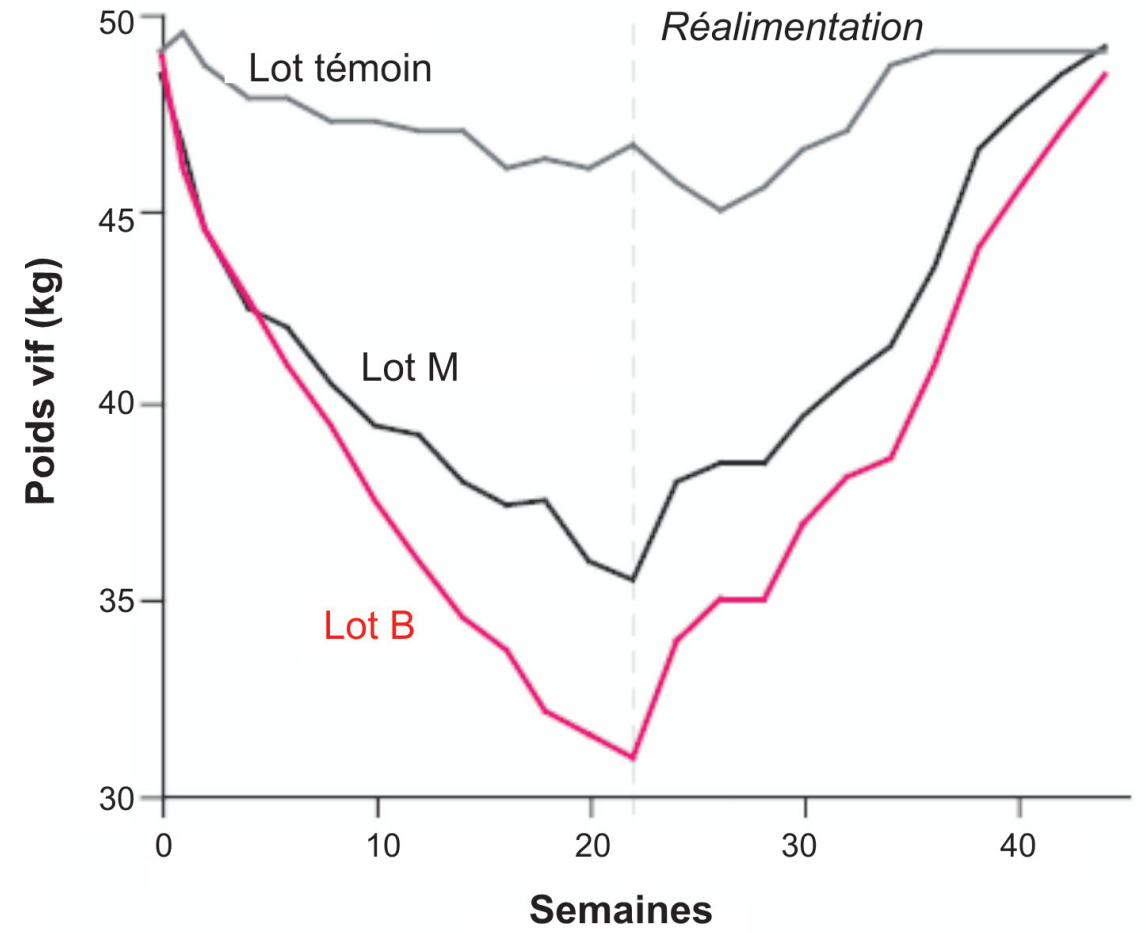

le cas d'une sous-alimentation absolue où le disponible alimentaire est limitant (c'est le cas notamment de la saison sèche en zone tropicale ou subtropicale) (Chilliard et al 1998, Blanc et al 2004). Seul ce second aspect, plus spécifiquement lié à l'adaptation aux régions chaudes, sera décrit dans cette synthèse.

En régions tropicales, des réponses adaptatives de type rebond sont observées lorsqu'une période de réalimentation succède à une phase de restriction alimentaire plus ou moins durable et sévère comme c'est le cas lors des saisons sèches en zones sahéliennes, qui peuvent durer 8 à 9 mois consécutifs. Cet effet rebond est susceptible d'induire des écarts de bilan alimentaire non négligeables. La réponse est d'autant plus forte que la durée et la sévérité de la restriction préalable ont été plus importantes (Blanc et al 2010). Par exemple, lorsqu'on compare deux stratégies d'alimentation sur le long terme appliquées à la brebis Barbarine (Atti et Bocquier 1999), une stratégie stabilisée consistant à ajuster les apports à un niveau permettant le maintien des brebis à poids constant et une stratégie dynamique consistant à les sousalimenter fortement (40 ou 20\% des besoins) pendant 22 semaines puis à les réalimenter pendant 23 semaines, jusqu'à revenir à leur poids vif initial (figure 3), on constate que les apports énergétiques totaux (156 UFL) sont inférieurs de $20 \%$ à ceux de la stratégie 
stabilisée (188 UFL) (Atti et Bocquier 1999, Blanc et al 2004). Cette différence peut s'interpréter par un accroissement de l'efficacité alimentaire résultant des mécanismes d'épargne de nutriments et de mobilisation des réserves mis en œuvre durant la sous-alimentation et la réalimentation (Blanc et al 2004, Chilliard et al 2004). La diminution de la masse et de l'activité métabolique des organes splanchniques pendant la phase de restriction alimentaire et la baisse des dépenses énergétiques associée pourrait également constituer un mécanisme d'adaptation à la sousalimentation (Chilliard et al 1998, Atti et al 2000).

La gestion des réserves corporelles chez le dromadaire se traduit par des changements notables du volume de la bosse, celle-ci représentant la principale source de réserves adipeuses de l'animal, qu'il peut mobiliser lors des périodes de sous-alimentation ou de jeûne prolongé (Bengoumi et al 2005). Globalement la mobilisation des réserves adipeuses chez le dromadaire répond aux mêmes mécanismes que chez les autres ruminants. Il semble cependant que cette mobilisation soit plus lente que pour les autres herbivores en cas de déficit énergétique, l'animal étant capable comme on l'a vu plus haut, de diminuer ses dépenses énergétiques en cas de besoin (Bengoumi et al 2005). Des observations similaires ont été effectuées chez la brebis barbarine à queue grasse en Tunisie (Atti et al 2004). Des brebis sous-alimentées (20\% de leurs besoins énergétiques) pendant plusieurs semaines ont survécu durant 161 jours et perdu $36 \%$ de leur poids vif dont $70 \%$ de leur masse adipeuse. Le gras sous-cutané (qui constitue la principale réserve adipeuse) a été mobilisé plus rapidement et plus intensément que le gras caudal, celui-ci intervenant comme réserve supplémentaire permettant de maintenir quasi constant le taux de mobilisation du tissu adipeux durant de longues périodes de sous-alimentation, telles que les saisons sèches des zones arides ou semi-arides.

Sur le plan du métabolisme énergétique, le dromadaire diffère des ruminants. En effet, les ruminants assurent l'essentiel de leurs besoins énergétiques à partir de la production d'acides gras volatils et produisent une faible quantité de glucose. Ceci explique la faiblesse de leur glycémie. Le dromadaire, en revanche, présente une glycémie de l'ordre de $1 \mathrm{~g} / \mathrm{L}$ soit une valeur comparable à celle des monogastriques. Par ailleurs, il présente une néoglucogénèse très active tant au niveau du foie que du rein, ce qui lui permet de maintenir une glycémie presque normale en cas de privation de nourriture. Chez les rumi- nants, le jeûne prolongé ou un déficit d'apports peut conduire à une accumulation de corps cétoniques comme le $\beta$-hydroxybutyrate dans le sang (acétonémie ou cétose). Chez le dromadaire, la cétogenèse est faible en toute circonstance. Le butyrate absorbé par l'animal au cours du cycle de transformation des acides gras volatils est directement utilisé par le rein comme source d'énergie, et par le tissu adipeux comme précurseur de la synthèse des acides gras (Emmanuel 1980).

- Economie et recyclage de l'azote. Chez les ruminants, la capacité de mobilisation des réserves protéiques (au maximum $15 \%$ de la masse protéique totale) est beaucoup plus réduite que celle des réserves adipeuses (jusqu'à $50 \%$ de la masse adipeuse totale). Il semble également que la vache ne soit pas capable de reconstituer intégralement la masse musculaire mobilisée au cours de cycles successifs de sousalimentation/réalimentation (Robelin et al 1990), contrairement à la brebis Barbarine qui est capable de reconstituer intégralement non seulement la perte de tissus adipeux mais également la perte de tissu musculaire (Atti et Bocquier 1999, Blanc et al 2004).

Une sous-alimentation protéique se traduit généralement par une réduction des pertes azotées urinaires et dans les cas extrêmes par un ralentissement ou un arrêt de la croissance de la laine chez le mouton (Chilliard et al 1998). Chez le dromadaire, la réduction des pertes azotées peut également être le résultat d'une augmentation des capacités de recyclage de l'urée par le rumen (Dulphy et al 1995). Plusieurs études ont ainsi montré que les races désertiques sont capables de maintenir la densité microbienne du rumen et la protéosynthèse ruminale en présence de fourrages médiocres, déficitaires en protéines. Cette aptitude est liée à leur grande capacité à recycler l'urée (Emmanuel 1980, Silanikove 2000). Le dromadaire a ainsi la capacité de recycler l'urée en proportion 2 à 3 fois plus importante que le mouton. La quantité d'urée excrétée devient ainsi très faible, $1 \%$ seulement, contre $23 \%$ chez le mouton. La chèvre bédouine est capable de recycler une quantité d'azote équivalente à une à deux fois l'azote ingéré (Silanikove 2000). C'est au niveau du rein que l'essentiel de l'urée est réabsorbé bien que le recyclage commence dans les glandes salivaires et surtout le rumen. Cette réabsorption est étroitement associée à celle de l'eau. Elle est sous la dépendance de l'hormone antidiurétique $(\mathrm{ADH})$ dont l'action permet en cas de déshydratation de diminuer la filtration glomérulaire et d'activer une forte réabsorption tubulaire de l'urée.
Celle-ci par ses effets osmotiques, permet d'attirer l'eau des autres milieux vers le plasma. De fait, la réabsorption active de l'eau dans le tube collecteur du rein s'accompagne de celle de l'urée (Bengoumi et Faye 2002). L'adaptation à une sous-alimentation protéique réside donc davantage dans la réduction des pertes azotées que dans la mobilisation des réserves protéiques.

- Utilisation efficace de l'eau. Les animaux boivent essentiellement pour remplacer l'eau perdue (par évaporation cutanée ou respiratoire ou par voie urinaire) et non pour couvrir leurs besoins futurs. La consommation d'eau est donc déterminée dans une large mesure par le niveau des pertes hydriques. Le danger de la déshydratation est lié à l'augmentation de la viscosité du sang, au ralentissement de la circulation et l'augmentation consécutive de la température suite à la diminution des transferts cutanés de chaleurs (King 1989).

L'eau de l'organisme participe au métabolisme biochimique intermédiaire et au refroidissement évaporatoire de l'organisme. Toutefois, le bétail élevé en régions chaudes consacre plus d'eau au processus de refroidissement par évaporation qu'à l'activité métabolique intermédiaire. Les ruminants des zones désertiques sont ainsi connus pour leur capacité à résister à des périodes prolongées de restriction hydrique et valoriser ainsi des zones de pâturage très éloignées des points d'eau. Les zébus sont régulièrement abreuvés tous les 3 jours. Certaines races de chèvres semblent encore plus résistantes comme les chèvres des zones désertiques du Sinaï qui sont abreuvées tous les 4 jours. Les dromadaires peuvent endurer des périodes de restriction encore plus longues, jusqu'à 15 jours (Silanikove 1994). Le dromadaire et la chèvre noire du désert sont capables de tolérer des pertes en eau corporelle correspondant à 25 et $40 \%$ de leur poids vif, respectivement, contre 18 et $20 \%$ pour les bovins et les ovins (Silanikove 1994).

La résistance à la déshydratation est liée pour partie à des mécanismes qui régulent la pression osmotique des protéines plasmatiques et maintiennent constant ou augmentent le volume de plasma (King 1989). Le pouvoir de rétention hydrique est plus élevé chez les espèces désertiques. Après abreuvement, le passage de l'eau des réservoirs gastriques vers le sang est 2 à 3 fois moins rapide et le début de l'élimination rénale de l'eau plus tardive $(24 \mathrm{~h} v s$ $4 \mathrm{~h})$ chez le dromadaire comparé au bovin (Siebert et Macfarlane 1971). La déshydratation entraîne une diminution du volume de salive secrétée (pouvant atteindre $20 \%$ du volume normal) qui 
provoque une augmentation de l'osmolarité du contenu ruminal et du sang et induit une diminution de l'ingestion (stimulation du centre de la satiété) (Morand-Fehr et Doreau 2001). Ces mécanismes se mettent toutefois en place plus tardivement, avec des niveaux de déshydratation plus élevés chez les espèces des zones désertiques (Silanikove 1994). Des travaux ont également montré que des chèvres bédouines en lactation présentent un volume plasmatique atteignant $8,5 \%$ de leur poids corporel contre $5 \%$ pour la plupart des autres ruminants (King 1989), ce qui leur permet de résister plus efficacement à des périodes prolongées de restriction hydrique.

Un second mécanisme d'adaptation réside dans l'aptitude à limiter les pertes hydriques urinaires (concentrations des urines, réduction du débit) et fécales. L'urine des dromadaires, des chèvres et de certaines espèces de mouton (mouton du désert, mouton à queue grasse) est 2,5 fois plus concentrée que celle des zébus (Maloiy 1972). Ces mécanismes d'adaptation permettent aux chèvres bédouines de tolérer une réduction $\mathrm{du}$ volume plasmatique de $40 \%$ lorsqu'elles sont exposées à la déshydratation (King 1989). De même, le dromadaire ou le mouton du désert peuvent tolérer une déshydratation voisine de $30 \%$ de leur poids corporel (King 1989). Il est intéressant de noter qu'une restriction hydrique diminue les pertes azotées dans l'urine et augmente le recyclage de l'urée au niveau du tube digestif (Brosh et al 1987).

\section{3 / Résistance aux maladies}

Cet aspect de l'adaptation a le plus souvent été abordé par la compréhension du contrôle génétique de la résistance chez les hôtes, tandis que la compréhension des mécanismes résulte secondairement de la connaissance de la variabilité observée. Des approches épidémiologiques ont également été réalisées pour mettre en évidence des facteurs de variation des risques d'exposition des hôtes aux pathogènes. Chez les monogastriques, ce caractère est rarement abordé spécifiquement pour les régions chaudes, la conduite hors-sol associée à la maîtrise chimique (désinfection) des pathogènes mettant au second plan ce sujet de recherche. Cependant, des différences entre races ont été mises en évidence dans des systèmes d'élevage plus extensifs, par exemple pour la résistance aux Strongles Gastro-Intestinaux (SGI) chez les volailles locales (Schou et al 2007, Kaufmann et al 2010). A l'heure actuelle, les firmes avicoles s'orientent plutôt vers la sélection de lignées robustes (Star et al 2008), c'est-à-dire des ani- maux ayant une grande capacité de survie et de récupération après une fluctuation de leur environnement (alimentation, et/ou température, et/ou bioagresseurs).

En grande majorité, les travaux sur la résistance génétique aux maladies concernent donc les ruminants. La variabilité génétique de la résistance à des maladies bactériennes (mammites, inflammation de la mamelle due à un Staphylocoque; piétin, infection des pattes due à Dichelobacter nodosus) a été étudiée en zone tempérée et donne lieu à des applications possibles en zone tropicale (Mirkena et al 2010). En zone tropicale, ce sont les travaux sur la résistance aux maladies parasitaires (trypanosome, tiques et maladies transmises, strongles) qui dominent, du fait du caractère endémique de la pathologie, des pertes économiques engendrées, et de l'absence d'alternative à la lutte chimique (Gauly et al 2010).

L'existence de variabilité pour le caractère résistance aux maladies est souvent constatée lorsque des populations d'animaux exotiques sont introduites dans des zones d'élevage traditionnelles où la population autochtone de ruminants ne montre pas de signes pathologiques apparents. Cette variabilité entre populations résulte de la sélection naturelle à laquelle les populations locales ont été soumises. L'analyse de la variabilité intra-race donne, quant à

Photo 3. Tique mâle gorgée Amblyomma variegatum.

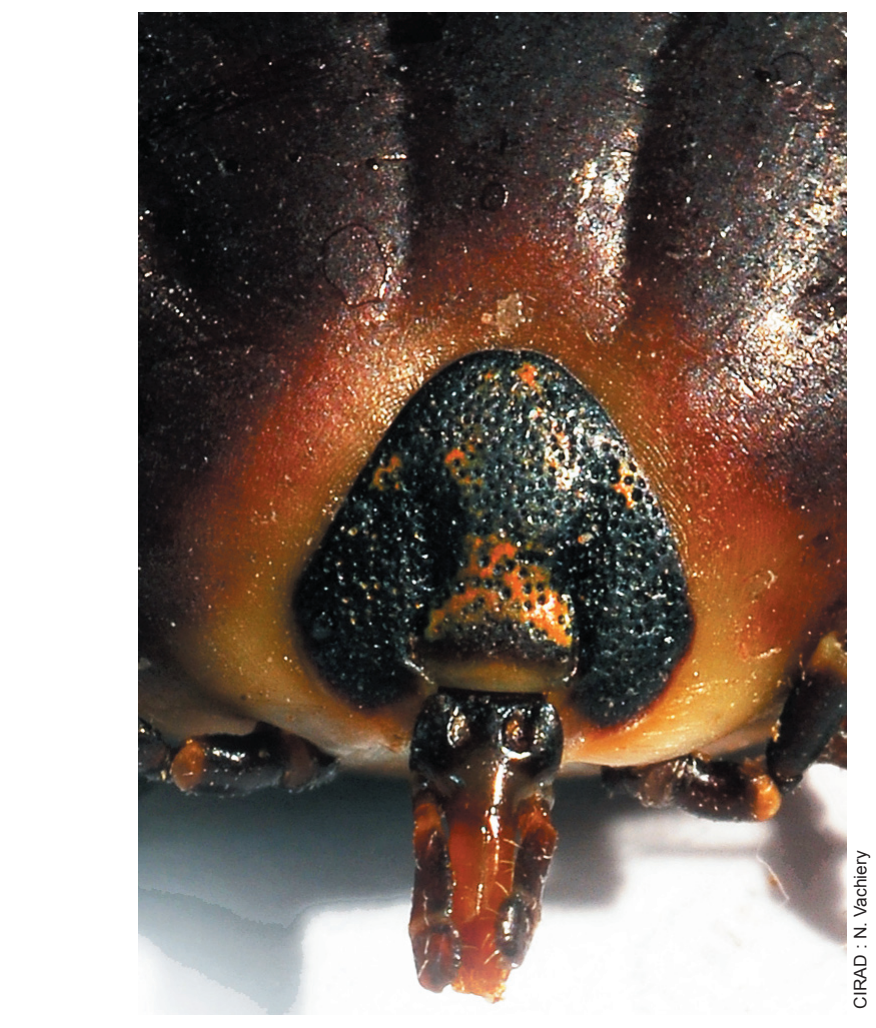

elle, accès à la compréhension plus fine des mécanismes impliqués dans l'adaptation et au développement d'outils pour la sélection.

La trypanotolérance est la capacité relative d'un animal à limiter le développement des trypanosomes (Trypanosoma congolense), parasites protozoaires extra-cellulaires du sang transmis par la mouche Tsé-Tsé, et de leurs effets pathogènes (anémie, cachexie et mort des animaux les plus sensibles). Elle constitue non seulement une caractéristique raciale mais également un caractère héritable au sein d'un cheptel. Des QTL (Quantitative Trait Loci) ont été détectés sur la parasitémie, le poids et le contrôle de l'anémie, en valorisant la tolérance des Bos Taurus N'Dama et la sensibilité des Bos Indicus Boran (Hanotte et al 2003, Dayo et al 2009). Gautier et al (2009) ont mis en évidence des signatures de sélection dans des populations trypanotolérantes d'Afrique de l'Ouest et proposent 42 gènes candidats associés à l'immunité, la régulation nerveuse et les protéines de la peau, et impliqués dans la trypanotolérance. Des gènes exprimés de façon différentielle en cours d'infestation chez des N'Dama et des Boran ont également été identifiés (O'Gorman et al 2009). La connaissance des mutations causales de la trypanotolérance découlera de la synthèse de ces différentes approches. 
Tableau 2. Sensibilité des bovins des Antilles françaises aux tiques et aux maladies associées (d'après Barré 1997).

\begin{tabular}{|c|c|c|c|c|}
\hline \multirow{2}{*}{ Tique } & \multirow{2}{*}{$\begin{array}{l}\text { Maladie } \\
\text { associée }\end{array}$} & \multicolumn{3}{|c|}{ Races bovines } \\
\hline & & Créole & Européennes & Brahman \\
\hline \multirow[t]{3}{*}{ Boophilus microplus } & & + & +++ & + \\
\hline & Babésiose & - & +++ & -- \\
\hline & Anaplasmose & -- & ++ & -- \\
\hline \multirow[t]{4}{*}{ Amblyomma variegatum } & & ++ & ++ & ++ \\
\hline & Cowdriose & -- & ++ & -- \\
\hline & \multirow[t]{2}{*}{ Dermatophilose } & Guadeloupe -- & +++ & +++ \\
\hline & & Martinique +++ & & \\
\hline
\end{tabular}

+ : sensibilité plus ou moins marquée ; - : résistance plus ou moins marquée.

Une moindre incidence des maladies peut aussi être obtenue par l'acquisition d'une résistance à leur vecteur. Ainsi, les Bos Indicus sont considérés comme plus résistants aux tiques que les Bos Taurus. L'utilisation d'animaux génétiquement résistants aux tiques constitue ainsi une méthode alternative au contrôle des maladies qu'elles transmettent. De nombreux travaux ont démontré l'existence d'une variabilité de la sensibilité aux tiques entre races bovines (Pegram et al 1993) mais peu rapportent une variabilité intra-race car les facteurs environnementaux ont un effet important sur l'infestation par la tique. Ces résultats sont prometteurs quant à la possibilité de sélectionner les bovins Créole sur leur résistance à la tique sénégalaise Amblyomma variegatum en condition d'infestation. Deux études ont montré une association entre les allèles DRB3 (dans la région BoLA) et le poids ou le nombre de tiques gorgées Amblyomma americanum (Untalan et al 2007) et Rhipicephalus microplus (Martinez et al 2006). D'autres travaux portant sur l'infestation de bovins par $R$. microplus (Gasparin et al 2007), ont mis en évidence des QTL de résistance associés différemment selon la saison. Ces résultats indiquent l'importance des interactions entre le génotype et l'environnement. Enfin, des analyses d'expression de gènes (Piper et al 2008, 2009, Kongsuwan et al 2008) semblent montrer une réponse immunitaire très différente durant la phase de fixation de la tique selon que l'hôte est de génotype sensible Bos taurus ou résistant Bos indicus.

En piquant les animaux, la tique inocule à son hôte des pathogènes pouvant causer des pertes importantes, comme par exemple Ehrlichia ruminantium, parasite sanguin très infectieux, ou Dermatophilus congolensis cause de lésions sévères de la peau. Le bovin Créole est en contact avec la tique $A$. variegatum depuis plus d'un siècle. La sélection naturelle et ses origines $B$. indicus semblent lui avoir apporté une bonne résistance aux maladies associées aux tiques (tableau 2), dont la dermato- philose de faible incidence également chez les zébus d'Afrique de l'Ouest élevés dans des zones endémiques (Barré et Woodman 1990). Une variabilité intra-race a aussi été observée et des marqueurs génétiques ont ainsi pu être identifiés : une association entre des haplotypes aux marqueurs BoLADRB3/DQB et la résistance de bovins Brahman en Martinique a été rapportée (Maillard et al 1999).

La cowdriose est une infection des cellules endothéliales par une rickettsia Ehrlichia ruminantium transmise par la tique Amblyomma aux ruminants. Elle est présente en Afrique subsaharienne, Madagascar et dans certaines îles de la Caraïbe. Elle provoque des troubles respiratoires, digestifs et des désordres neurologiques et est le plus souvent mortelle pour des ruminants n'ayant jamais été en contact avec la bactérie. En revanche, là où la cowdriose sévit de manière endémique, certaines populations de ruminants ne sont pas atteintes par cette maladie (tableau 2). Chez les caprins Créole de Guadeloupe, une variabilité génétique a été mise en évidence pour l'intensité des réactions cliniques, la vitesse de progression de la maladie et la mortalité induite (Bambou et al 2010b). Obexer-Ruff et al (2003) ont montré une possible influence de marqueurs de MHC de type I sur la résistance à la cowdriose dans cette population Créole. Par ailleurs, des niveaux élevés de INF $\gamma$ ont été associés à une inhibition du développement du pathogène dans les cellules cibles (Esteves et al 2004).

C'est pour la résistance aux strongles gastro-intestinaux que l'effort de recherche et les connaissances accumulées sont les plus nombreuses, en raison de l'impact économique de la maladie en zone tropicale (Fabiyi 1987) comme en zone tempérée. Dans la zone tropicale humide et les systèmes de production intensifs où les parasites trouvent des conditions favorables à leur développement (Aumont et al 1991), la prévalence de la maladie atteint $100 \%$. Les pertes (retards de croissance, mortalité, chute de fertilité) sont plus importantes chez les petits ruminants que chez les bovins car, après sevrage, l'immunité des veaux contre les SGI semble bien établie (Aumont et al 1991). Pour les caprins Créole de Guadeloupe, la productivité à un an des animaux infestés est inférieure de $30 \%$ à celle des non infestés (Mandonnet 2009). L'obtention d'animaux résistants et la réduction concomitante de la charge parasitaire des pâturages constituent un moyen d'amélioration des productions tout en diminuant le nombre de traitements anthelminthiques (Mahieu et al 2009). Par ailleurs, les petits ruminants peuvent limiter leur niveau d'infestation par les SGI en consommant préférentiellement des plantes à tanins par exemple (Provenza 2008, Villalba et al 2010).

Au sens strict, la résistance se définit comme la capacité d'un animal à limiter la taille de la population vermineuse hébergée. Elle ne préfigure pas systématiquement de sa tolérance, aptitude de l'animal à survivre aux effets pathogènes du parasitisme (Albers et al 1987), ni de sa résilience, aptitude de l'animal à maintenir sa production en niveau subclinique d'infestation. Des différences de résistance entre populations de petits ruminants ont été observées dans tous les grands types de systèmes de production (tropical ou tempéré) et pour une grande variété d'espèces parasites ( $H$. contortus, $T$. colubriformis, T. circumcincta, $O$. columbianum, Nematodirus sp.), en infestation artificielle ou naturelle. Les races identifiées comme résistantes sont souvent des races locales (Baker et Gray 2003), en raison d'une plus forte pression de sélection naturelle par les parasites en l'absence de traitement et d'un équilibre avec leur milieu (moutons Florida Native, Gulf Coast Native, Blackbelly et Sainte Croix). La majorité des recherches se sont attachées ensuite à quantifier la variabilité génétique disponible intra-populations (de la Chevrotière et al 2009a) en vue d'inclure ce caractère dans les schémas de sélection. Les résultats suggèrent une 
Photo 4. Vers adultes mâle et femelle d'Haemonchus contortus.

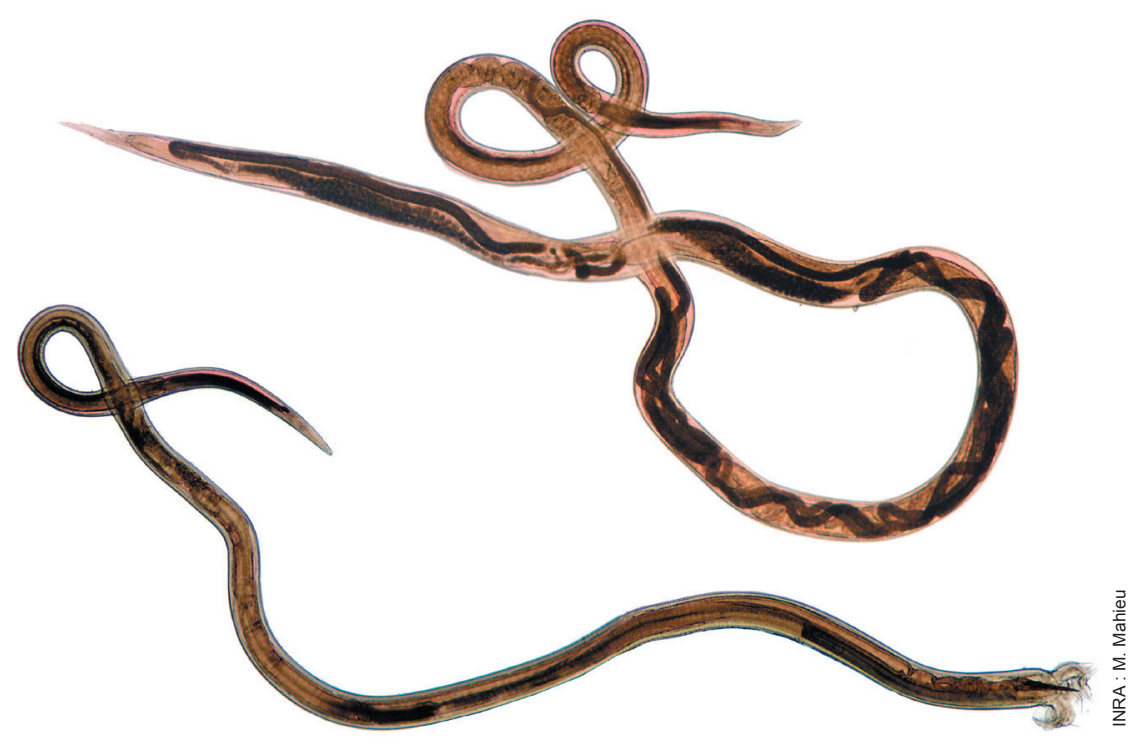

héritabilité moyenne (comprise entre 0,20 et 0,30 ), quels que soient le génotype de l'hôte, le mode d'infestation ou l'espèce de parasite. Des gènes communs s'expriment à différents stades de production et des relations favorables entre résistance et poids ou production de laine sont généralement rapportées. La spécificité de la résistance ne semble pas si étroite avec la souche de parasite voire même avec l'espèce de parasite (Gruner et al 2004, Bambou et al 2010a). En Australie, ces recherches ont permis la mise en place d'un service nommé WormBoss, développé par l'Australian Sheep Industry Cooperative Research Centre (Sheep CRC) et 1'Australian Wool Innovation (AWI), pour aider les éleveurs à contrôler les populations vermineuses dans leurs élevages et à sélectionner les béliers résistants aux SGI. Des travaux australiens de sélection expérimentale de moutons Mérinos résistants aux nématodes gastro-intestinaux, aux myiases cutanées et au piétin sont également conduits. En Guadeloupe, le schéma de sélection en cours de mise place pour les caprins Créole (Gunia et al 2010a et b) prendra en compte à la fois des caractères de production de viande et la résistance aux SGI.

Les techniques de génomique ont permis une évolution notable dans la caractérisation des mécanismes de résistance aux SGI. Les différents QTL trouvés amènent à analyser la composante immunitaire de la résistance. Chez les bovins, une récente recherche de QTL (Coppieters et al 2009) a mis en évidence 4 QTL associés à l'excrétion d'œufs de strongles. Un génotypage fin dans les régions détectées semble impliquer un gène ITAGE codant pour des protéines de surface des lymphocytes T impliqués dans la réponse immunitaire aux pathogènes de l'intestin. Chez des bovins Angus, Araujo et al (2009) ont montré l'expression différentielle de 100 gènes associés à 10 fonctions (immunoglobulines, chemokines, communication et cycle cellulaires, compléments et molécules d'adhésion). Chez les petits ruminants, la majorité des résultats QTL publiés à ce jour concerne l'espèce ovine (Crawford et al 2006, Moreno et al 2006, Bishop et Morris 2007). Deux études concernent les caprins (de la Chevrotière et al 2009b, Bolormaa et al 2010). La région la plus intéressante serait liée à l'INF $\gamma$ mais, par ailleurs, les QTL détectés semblent très dispersés sur tout le génome ce qui suggère que la résistance a fondamentalement un déterminisme polygénique chez les petits ruminants. Les études d'expression en ovins aboutissent à une meilleure connaissance de la réponse immune des ovins vis-à-vis des strongles (Terefe et al 2007). La résistance génétique induit la prolifération de mastocytes, de globules blancs et éosinophiles dans la muqueuse gastro-intestinale. Cette réponse produit des immunoglobulines $A, G 1$ et $E$ spécifiques. La réponse innée serait primordiale pour le développement de la résistance à $H$. contortus, alors que la réponse acquise le serait plus pour T. colubriformis (Ingham et al 2008). Les premières hypothèses de mécanisme ont été avancées en chèvre Créole (Bambou et al 2009). Malgré tout, les hypothèses restent nombreuses quant à l'enchaînement des mécanismes et l'identification du mécanisme dominant, décisif dans cette chaîne. L'aspect de la polarisation entre réponse immune de type TH1 (associée à l'activation des macrophages) ou
TH2 (associée à l'activation des lymphocytes B) vis-à-vis des strongles est encore controversé, certaines études montrant une polarisation TH2 (Gill et al 2000) et d'autres un équilibre (Araujo et al 2009). C'est une des voies prioritaires d'investigation.

A travers les exemples cités, il apparaît que les populations animales tropicales sont des sources incontournables de connaissances génériques sur les mécanismes physiologiques, comportementaux et génétiques de l'adaptation au milieu, car elles s'adaptent à des niveaux de contraintes extrêmes par rapport à ce qui est observé en zone tempérée. Elles permettent ainsi d'explorer des réponses adaptatives non mises en œuvre sous d'autres latitudes. Le développement des outils de la génomique devrait accélérer la compréhension de ces réponses et ouvrir la possibilité d'une sélection génomique grâce à l'identification des populations tropicales résistantes/tolérantes et porteuses de signatures de sélection. La compréhension de ces caractères est par ailleurs un levier important pour gérer les contraintes environnementales et améliorer durablement les capacités adaptatives des animaux en milieu tropical.

\section{2 / Optimisation de la pro- ductivité et de la résilience des systèmes d'élevage tro- picaux}

Depuis la domestication, l'Homme n'a eu de cesse de protéger son cheptel des prédateurs, de réguler son approvisionnement en nourriture et d'orienter sa reproduction afin d'augmenter sa productivité (Mignon-Grasteau et al 2005). Dans certains systèmes d'élevage, l'Homme a mis à profit l'aptitude des animaux à s'adapter à divers jeux de contraintes. Dans l'élevage moderne, la gestion des contraintes de l'environnement doit se concevoir de façon intégrée pour être biologiquement et économiquement durable. Elle doit ainsi combiner différentes techniques d'alimentation, de gestion d'ambiance, de santé pour limiter les pertes de production et doit améliorer l'adaptation des animaux à leur environnement. Il en résulte une optimisation de la productivité et non plus une augmentation absolue. Les pratiques d'élevage et la génétique sont les deux leviers possibles de cette optimisation.

\section{1 / Choisir une conduite d'éle- vage atténuant les contraintes environnementales}

Selon la contrainte, les éleveurs peuvent soit soustraire partiellement leurs 
animaux à l'environnement, soit augmenter leurs capacités d'adaptation, principalement via une meilleure alimentation.

a) Soustraire les animaux aux contraintes du milieu

- Par un aménagement de l'environnement d'élevage. Pour lutter contre les effets de la chaleur chez les monogastriques, les méthodes qui permettent d'augmenter la capacité des animaux à perdre de la chaleur ou de refroidir l'ambiance des bâtiments peuvent être utilisées efficacement. L'amélioration des capacités de thermolyse sont généralement obtenues en augmentant les pertes de chaleur latente par un apport d'eau sur l'animal (pulvérisation ou goutte à goutte), ou via l'aménagement dans les loges d'élevage d'un point d'eau permettant aux animaux de s'y baigner (McGlone et al 1988). Les pertes de chaleur sensibles (convection, conduction) peuvent être améliorées en augmentant la vitesse de l'air à proximité de l'animal (ventilation). Yahav et al (2004a) définissent l'optimum de confort thermique pour les poulets autour d'une ventilation de $2 \mathrm{~m} / \mathrm{s}$ à $35^{\circ} \mathrm{C}$ et une hygrométrie de $60 \%$. Les pertes de chaleur sensible peuvent également être augmentées en aménageant une zone de couchage où le sol est refroidi. Cette dernière technique permet d'augmenter significativement la consommation d'aliment notamment chez la truie en lactation exposée à une forte température (Silva et al 2009). Dans le cas d'un élevage sur parcours, il est recommandé d'aménager une zone d'ombrage. Ces systèmes sont généralement peu coûteux et bien adaptés aux conditions d'élevage tropical. Diminuer la densité animale pour limiter les transferts de chaleur par radiation entre animaux et limiter les manipulations d'animaux aux heures chaudes sont également des pratiques qui optimisent la production de monogastriques en situation de contrainte thermique. A l'échelle du bâtiment, la diminution de la température ambiante est classiquement obtenue par des systèmes basés sur des échanges air/eau où l'absorption d'énergie par l'eau nécessaire pour passer de l'état liquide à l'état gazeux se traduit par une diminution de la température de l'air. Les deux équipements les plus utilisés sont la brumisation (fogging) et les filtres humides (Pad cooling) qui se sont généralisés ces dernières années en élevage avicole industriel. Pour être efficaces ces systèmes doivent être utilisés dans des bâtiments très bien isolés ce qui est rarement le cas en régions tropicales où la plupart des élevages sont de type semi-ouverts. Ainsi, le fogging et le pad cooling sont adaptés pour lutter contre les effets des coups de chaleur estivale mais le sont moins pour atténuer les effets d'une exposition chronique aux fortes températures. De ce fait, l'orientation des bâtiments estouest, l'emploi de matériaux réfléchissants et de couleurs claires, la circulation d'air sont aussi des éléments à prendre en compte pour la régulation de la température au niveau des animaux.

Dans des conditions d'élevage tropicales humides, un compromis sera recherché entre la résistance au stress thermique et le niveau de production, tous deux liés négativement : mise à la disposition des animaux d'abris, arrosage et ventilation, augmentation de la densité énergétique de la ration, apport d'une source d'azote fermentescible lorsque celle-ci est le facteur limitant de la digestion des fourrages, et augmentation du bilan cation-anion de la ration (Morand-Fehr et Doreau 2001). Une partie de l'adaptabilité des races exotiques réside certainement dans leur faculté à mettre en adéquation leur rythme de reproduction, et/ou leur niveau de production, avec les contraintes environnementales et, de fait, à s'éloigner des limites physiologiques habituellement retenues comme objectifs de production dans les systèmes d'élevage intensifs.

- Par le choix d'une conduite d'élevage prenant en compte les contraintes du milieu. Dans le cas du dromadaire, la pratique du pâturage ambulatoire est particulièrement adaptée à la gestion et la préservation des ressources ali- mentaires limitées dans les milieux désertiques. D'autres espèces comme la chèvre montrent des capacités adaptatives élevées à valoriser les ressources naturelles non utilisées par les autres ruminants domestiques par leur comportement alimentaire sélectif et l'efficacité de l'utilisation des ressources fourragères. L'étude du régime alimentaire de caprins et de bovins conduits en pâturage mixte sur des savanes naturelles plus ou moins dégradées (Martinique) montre que la compétition bovins/caprins est bénéfique et entraîne une consommation accrue par les caprins d'espèces indésirables (adventices, plantes riches en tannins) et que la complémentarité alimentaire des deux espèces permet d'obtenir un chargement plus élevé tout en évitant l'embroussaillement des parcelles (Biquand et Biquand-Guyot 1991, Daoramola et Adeloye 2009). La compréhension du comportement spatial et alimentaire des troupeaux et des interactions animalressource permet également de formuler des recommandations dans la gestion des couverts naturels et le positionnement d'aménagements pastoraux (points d'eau, abris, parcs de nuit) afin de préserver la diversité des ressources et de maximiser les performances animales et les transferts de fertilité sur le territoire (Bailey et al 1998, Chirat et al 2009).

Dans le cas de l'élevage des petits ruminants, la stratégie de lutte contre les parasites gastro-intestinaux (contrainte majeure de la conduite au pâturage)

\section{Photo 5. Pâturage mixte de bovins et caprins Créole en Guadeloupe.}

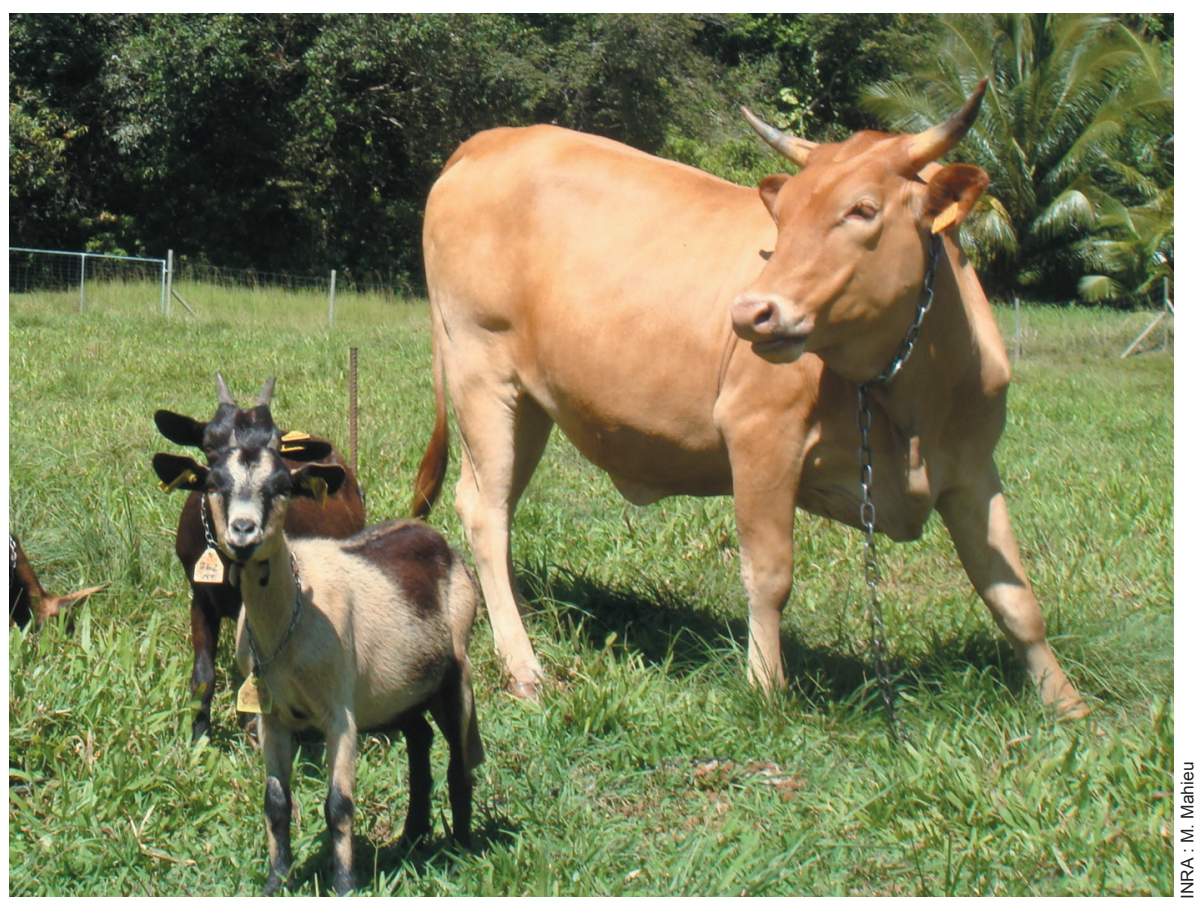


visait, jusqu'à très récemment, à éradiquer les parasites des troupeaux par une utilisation systématique de traitements anti-parisitaires. Cette stratégie a induit l'apparition des résistances multiples aux anthelminthiques sous toutes les latitudes (Sangster 1999). Depuis quelques années, une logique reposant sur l'analyse des équilibres hôtes-parasites dans les systèmes pâturés (Mahieu et al 2009) a été développée, privilégiant ainsi la combinaison de diverses techniques d'élevage: traitements ciblés sur les animaux les plus sensibles, réduction des opportunités de rencontre entre hôtes et parasites, renforcement des défenses de l'hôte (cf. 2.1b).

La première stratégie vise à traiter de façon ciblée les animaux les plus atteints. La méthode Famacha $($ ) (Bath et al 1996, Mahieu et al 2007) diagnostique l'anémie provoquée par $H$. contortus, quand cette espèce est majoritaire et ne nécessite pas d'analyse en laboratoire. D'autres méthodes tendent à analyser les symptômes plus frustres provoqués par des associations de strongles non hématophages (chutes anormales de croissance (Besier 2005) ; consistance des fèces (Broughan et Wall 2007)). Les animaux non traités jouent alors le rôle de refuge permettant le maintien d'une population de strongles porteurs d'allèles de sensibilité aux molécules utilisées (Van Wyk 2001). Le traitement des animaux malades peut également être conçu en utilisant des plantes à vertu anthelminthique. La phytothérapie valorise certains composés secondaires (tanins par exemple) de plantes pouvant être elles-mêmes des fourrages comme les légumineuses, des coproduits de récolte (feuilles de manioc ou de bananier) (MarieMagdeleine et al 2009).

La deuxième stratégie vise à limiter les contacts entre les parasites et leurs hôtes potentiels. En faisant pâturer simultanément ou alternativement des animaux sensibles et des résistants (petits ruminants/bovins, jeunes/ adultes, mères allaitantes/mères gravides...), ce qui permet une dilution des larves infestantes sur le pâturage. Le niveau d'infestation du pâturage est alors considérablement diminué et les gains de production peuvent dépasser $10 \%$, sans coût supplémentaire (Mahieu et al 1997). D'autres techniques comme l'utilisation de champignons nématophages ou de microfaune coprophage (vermicompost) peuvent aussi permettre une réduction importante de la contamination larvaire des pâtures, mais elles nécessitent en amont une production importante de spores et de compost (Chandrawathani et al 2002, d'Alexis et al 2009). Ces méthodes industrielles ne sont pas encore
Figure 4. Les effets d'une alimentation alternée (dual-feeding) en millet entier le matin/concentré l'après-midi et d'un aliment complet à base de millet sur le nombre d'œufs par poule, la masse d'œuf par jour ( $g / j)$ et sur l'efficacité alimentaire (masse d'œuf/consommation d'aliment, \%) en conditions de températures cycliques élevées au Nigéria (d'après Umar Faruk 2010).

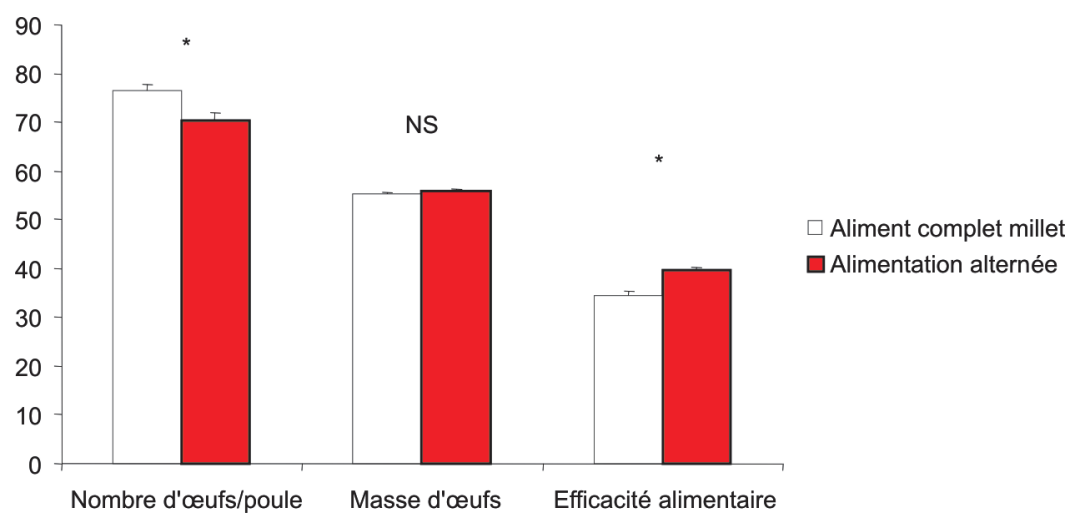

opérationnelles pour des systèmes d'élevage à faible niveau d'intrants.

- Par le choix d'une alimentation réduisant les effets du stress thermique. Le principe des solutions nutritionnelles est de modifier la composition de l'aliment pour augmenter l'ingestion d'énergie nette en diminuant la chaleur associée à l'utilisation digestive et métabolique de l'aliment (extrachaleur) ou en augmentant la densité énergétique de la ration. L'extra-chaleur associée à l'utilisation des protéines est supérieure à celle de l'amidon et des lipides (Noblet et al 1994). Ainsi la formulation d'aliment à faible teneur en protéines avec ou sans ajout de matières grasses permet d'obtenir des régimes ayant une faible extra-chaleur, (Temim et al 1999, Tesseraud et Temim 1999, Noblet et al 2001). En pratique, l'efficacité de ces régimes varie en fonction de la méthode utilisée pour formuler ces aliments (complémentation en acides aminés de synthèse, respect d'un rapport optimal entre les acides aminés indispensables et l'énergie, choix du système énergétique), des conditions dans lesquelles ont été réalisées les expérimentations (station expérimentale vs élevages commerciaux) et du poids ou du stade physiologique des animaux (Renaudeau et al 2008). Ainsi, l'utilisation de régimes à faible extra-chaleur semble être plus efficace chez la truie en lactation comparativement au porc en croissance (Renaudeau et al 2008). Chez les volailles, ces méthodes sont relativement peu efficaces et souvent plus coûteuses à mettre en œuvre. L'augmentation de la densité énergétique de l'aliment a été classiquement testée en complémentant l'aliment avec des matières grasses végétales ou animales. Plusieurs études ont été menées chez le poulet de chair et la poule pondeuse (Dale et Fuller 1980, Tanor et al 1984). Cela améliore le gain de poids ou limite la détérioration des performances de ponte (associé à une supplémentation en calcium chez la poule) mais chez le poulet de chair l'engraissement est accru. L'intérêt de ces aliments en conditions chaudes a été confirmé chez les porcs en finition (amélioration de la croissance) et chez la truie en lactation (augmentation de la production de lait) (Renaudeau et al 2008). Ces solutions nutritionnelles n'atténuent que partiellement les effets de la chaleur sur les performances et induisent un surcoût du prix de l'aliment qui peut limiter pratiquement le recours à de telles techniques. Récemment Umar Faruk et al (2010) ont testé les effets d'une alimentation alternée (dual feeding) en millet entier (riche en protéines) le matin/ concentré l'après-midi en conditions de températures cycliques élevées au Nigéria. L'alimentation séquentielle améliore alors l'efficacité alimentaire des poules $(+15 \%)$ mais diminue la production d'œufs par poule de $8 \%$ (sans modifier la masse d'œuf par jour), en comparaison avec un régime complet à base de millet (figure 4). Contrairement aux autres espèces, les techniques permettant de complémenter un aliment pour tenir compte des besoins spécifiques d'un animal soumis à un stress thermique (minéraux, vitamines, probiotiques) ont très peu été étudiées chez le porc. Chez les volailles, il est recommandé d'ajouter des ions $\left(\mathrm{NH}_{4} \mathrm{CL}, \mathrm{HCL}\right.$ ou $\left.\mathrm{KCL}\right)$ dans l'eau d'abreuvement pour augmenter la consommation d'eau et améliorer les équilibres ioniques (Borges et al 2004).

L'eau est le nutriment le plus important chez des animaux soumis à un stress thermique compte tenu notamment des besoins pour la thermorégulation (évaporation). Le rationnement hydrique ou l'apport d'une eau de mauvaise qualité va accentuer les effets de 
la chaleur sur les performances. Au contraire, un apport d'eau froide va permettre à l'animal de mieux supporter la chaleur ce qui va se traduire par une ingestion plus importante (Jeon et al 2006). L'adjonction d'eau dans la ration peut également permettre d'améliorer les performances au chaud. Pour Bos Indicus, la consommation d'eau passe de $3 \mathrm{~kg} / \mathrm{kg}$ de MS ingérée à $10^{\circ} \mathrm{C}$ à environ $10 \mathrm{~kg}$ à $35^{\circ} \mathrm{C}$ (NRC 1981) alors que pour Bos Taurus, la consommation à ces deux températures est d'environ 3 et $14 \mathrm{~kg} / \mathrm{kg}$ MS ingérée. Une partie de l'eau consommée vient du fourrage, dont la teneur en eau dépend aussi de facteurs climatiques. Il est donc important de veiller à l'approvisionnement en eau pour éviter de pénaliser la production. La distribution de fourrage à taux d'humidité élevé comme les troncs de bananier ou des raquettes de cactus inerme peut constituer un moyen efficace de compenser un moindre accès à l'eau.

L'aptitude des ruminants à modifier leur comportement alimentaire lors de stress thermique peut être utilisée pour limiter les baisses de consommation : pâturage aux heures les plus fraîches (la nuit), multiplication des prises alimentaires, réduction de leur durée, ou modification des choix alimentaires (ingestion sélective des plantes aqueuses, pauvres en constituants pariétaux et riches en azote) (Morand-Fehr et Doreau 2001).

- Par le choix d'une conduite de la reproduction pérennisant les troupeaux. En milieu tropical humide, Jordan (1992) rapporte que chez les animaux de races améliorées, protégés des variations du disponible alimentaire, les effets des fortes températures sur la reproduction se traduisent par une densité de vêlage supérieure entre septembre et décembre, correspondant à des fécondations de saison fraîche. En revanche, chez les animaux de race zébu Créole, moins sensibles aux fortes chaleurs, la saisonnalité de la reproduction n'est pas influencée par l'environnement thermique mais liée aux variations du disponible fourrager (Gauthier et al 1984, Jordan 1992), avec des fécondations concentrées entre août et novembre (saison chaude et humide). Le calage de la reproduction et du pic de production en saison fraîche, en particulier ceux de races exotiques à haut potentiel, constituent donc un moyen efficace pour lutter contre le stress thermique, à condition de mettre en adéquation la disponibilité des ressources herbagères et les besoins des animaux et de ne pas pénaliser les stratégies de commercialisation des producteurs. L'implantation des élevages en altitude est également un moyen radical pour compenser l'augmentation des températures.

Figure 5. Variations de la température corporelle en fonction de la température ambiante chez les poulets avant $(\mathrm{J} 35,0)$ et après stimulation thermique $(\mathrm{J} 38, \mathbf{0})$ (d'après Leterrier et al 2009).

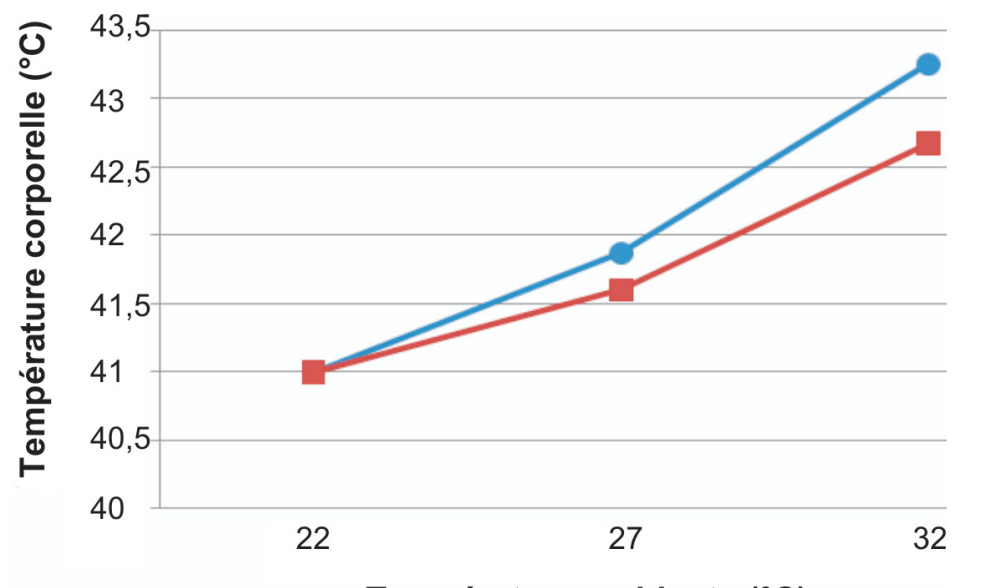

Température ambiante $\left({ }^{\circ} \mathrm{C}\right)$

Les éleveurs peuvent mettre en œuvre des trajectoires productives chez les femelles reproductrices différentes selon le contexte climatique et leur propre stratégie. En situation difficile, l'objectif de l'éleveur est souvent la pérennisation du troupeau reproducteur face aux aléas climatiques et alimentaires. En zone sahélienne, les brebis sont en présence des mâles en permanence (lutte continue) ce qui induit des trajectoires productives individuelles variées au sein d'un même troupeau, définies, sur un pas de temps pluriannuel, par une succession de phase de production et de phase d'infertilité. Sur les hauts plateaux boliviens, les éleveurs ne font faire qu'une mise bas tous les 2 ans aux femelles lamas pour limiter les effets des fluctuations alimentaires sur la mortalité des femelles adultes (Tichit et al 2008). Ces exemples sont assez emblématiques du rôle des pratiques de conduite du troupeau dans l'adaptation des animaux à leur environnement et dans les modalités de gestion du risque par l'éleveur.

\section{b) Augmenter les capacités d'adapta-} tion des animaux

Des techniques innovantes comme l'acclimatation et la vaccination sont à explorer. L'alimentation joue également un grand rôle dans l'expression des capacités adaptatives des animaux d'élevage, quelle que soit la contrainte.

- L'acclimatation à la chaleur. Il s'agit d'une exposition préventive et maîtrisée à un stress thermique, qui ultérieurement augmente la tolérance des poulets à ce stress. Pendant la croissance, Leterrier et al (2009) ont montré que la pré-exposition de courte durée à 27 puis à $32^{\circ} \mathrm{C}$ avant un coup de chaleur à $32^{\circ} \mathrm{C}$ limite d'environ $0,5^{\circ} \mathrm{C}$ l'augmen- tation de température interne lors du dernier stress thermique à $32^{\circ} \mathrm{C}$ (figure 5). Mais la conséquence d'une acclimatation pendant la phase de croissance est une diminution des performances de l'animal. Pour améliorer la thermotolérance sans détériorer le gain de poids ou l'indice de consommation, l'acclimatation périnatale à la chaleur peut être appliquée chez le poulet de chair à croissance rapide. Entre 3 et 5 jours post-éclosion, une exposition de $24 \mathrm{~h}$ à $38-40^{\circ} \mathrm{C}$ au lieu de $33^{\circ} \mathrm{C}$ améliore la survie lors d'un coup de chaleur à 35 ou 42 jours (De Basilio et al 2001, Yahav et McMurtry 2001). Ceci serait lié à des modifications épigénétiques. Une solution plus facile à appliquer en élevage pourrait être l'acclimatation embryonnaire directement effectuée dans l'incubateur. Plusieurs durées et périodes d'acclimatation ont été testées pendant l'embryogenèse (Yahav et al 2004a, Collin et al 2005, 2007). Les conditions optimales d'acclimatation qui perdurent à long terme sont de $12 \mathrm{~h} / \mathrm{j}$ à $39,5^{\circ} \mathrm{C}$ et $65 \%$ d'humidité relative (HR) entre les jours 7 et 16 de l'embryogenèse ( $v s$ $37,8^{\circ} \mathrm{C}$ et $56 \% \mathrm{HR}$ continus) pour le poulet de chair de souche Cobb (Piestun et al 2008, 2009). L'applicabilité de ces méthodes est actuellement en cours de validation à grande échelle.

- La voie vaccinale. Dans le cas des résistances aux pathologies (cowdriose, strongyloses), les défenses de l'hôte peuvent être stimulées par voie vaccinale. Les nombreuses tentatives de mise au point de vaccin anti $H$. contortus n'ont pas abouti à ce jour, en particulier à cause de la diversité des situations de polyparasitisme (Vercruysse et al 2004). C'est également la difficulté rencontrée dans l'élaboration du vaccin inactivé anti-cowdriose où la protection du vaccin semble très spécifique à chaque 
Figure 6. Evolution du taux moyen de fécondation mensuel (\%) avec l'état corporel moyen (échelle 0-5) de vaches Ndama multipares, Sénégal (Ezanno et al 2005).

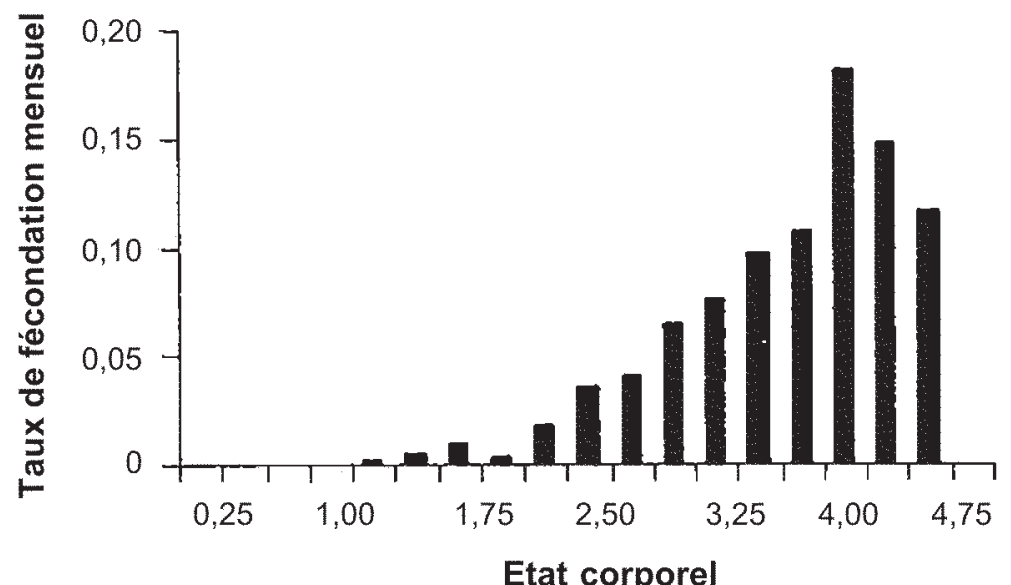

souche d'Erhlichia ruminantium (Adakal et al 2010). La difficulté est de sélectionner les souches ayant l'effet protecteur le plus large possible contre les souches circulant dans une région donnée. La constitution d'un cocktail de souches serait une alternative si aucun marqueur génétique fiable de protection croisée ne pouvait être mis en évidence.

- Choix d'une alimentation adaptée pour limiter la sensibilité au parasitisme. Chez un animal en équilibre avec son environnement, les ressources nutritionnelles sont allouées de façon équilibrée entre caractères d'homéorhèse (survie de la descendance, production) et d'homéostase (adaptation, fitness). En présence d'une contrainte biotique ou abiotique, cet équilibre peut être rompu en faveur de la production (s'il s'agit d'un animal sélectionné pour un caractère de production) ou en faveur de l'adaptation (s'il s'agit d'un animal soumis à sélection naturelle). Des apports nutritionnels ciblés peuvent rétablir l'intégrité des fonctions d'adaptation ou de production. C'est le cas des petits ruminants élevés au pâturage où la voie alimentaire de maîtrise du parasitisme gastro-intestinal vise à augmenter les défenses naturelles de l'hôte. Les effets favorables d'une alimentation équilibrée sont démontrés sur la résistance des petits ruminants. Une complémentation protéique et/ou énergétique des jeunes permet de mieux supporter les effets du parasitisme et de renforcer leurs défenses immunitaires (Bambou et al 2008). Chez des brebis complémentées en protéines métabolisables (MP) autour du parc, l'augmentation des leucocytes circulants et des Immunoglobulines E plasmatiques anti-larves infestantes traduit l'amélioration de la réponse immunitaire vis-à-vis des strongles. Il s'ensuit une diminution de l'excrétion d'œufs et de la taille de la population vermineuse hébergée (Houdijk et dues en début de lactation pour la préparation d'une nouvelle gestation.

Le comportement sexuel constitue également une voie de régulation de la réponse des femelles à la sous-nutrition (Blanc et al 2004). En cas de restriction alimentaire sévère $(40 \%$ des besoins énergétiques couverts), l'activité ovarienne cyclique est maintenue alors que la durée de l'œstrus est nettement raccourcie, ce qui réduit d'autant la probabilité de saillie par les béliers et le risque d'un démarrage d'une nouvelle gestation dans des conditions nutritionnelles précaires (Blanc et al 2004). Une réalimentation ou une complémentation ponctuelle à la mise à la reproduction (flushing) permet dans ce cas de lever cette infertilité comportementale.

\section{2 / Développer et exploiter les capacités génétiques d'adapta- tion des animaux d'élevage}

Le développement durable des productions animales en zone tropicale reposera sur l'utilisation de l'adaptation naturelle des populations animales indigènes (Wilson 1998) et sur l'inclusion des caractères d'adaptation dans les objectifs de sélection des races locales ou spécialisées (Franklin 1986, Baker et Rege 1994, Hoffmann 2010, Mirkena et al 2010). Cependant, l'intérêt de l'adaptation au milieu difficile des populations animales indigènes et la haute technicité requise pour les races importées ne sont pas bien appréhendés par les éleveurs, ni même par les techniciens du développement (FAO 2008). Les éleveurs de ruminants allaitants, par exemple, sont plus sensibles à une augmentation rapide du gabarit et de la vitesse de croissance de leurs animaux. Or, ces critères sont contre-productifs en termes de production annuelle de viande (Figueiredo et al 1989), particulièrement si l'accès à l'alimentation est limité.

Les races locales de la zone tropicale constituent ainsi des réservoirs de gènes d'un intérêt primordial dans le contexte à venir, notamment pour la résistance aux maladies et l'adaptation aux contraintes climatiques (FAO 2008, Hoffman 2010). Pour développer leurs capacités génétiques d'adaptation ou celles des races spécialisées importées, trois points sont à analyser : le choix des objectifs et critères de sélection, la stratégie d'amélioration (intra-race, substitution ou croisement) et l'organisation pratique de la diffusion du progrès génétique.

a) Quels objectifs et critères de sélection faut-il prioriser?

Il existe deux voies principales pour l'amélioration génétique de la production et de l'adaptation du cheptel en 
milieu tropical : la sélection directe et la sélection indirecte. La première prend en compte l'adaptation et ses relations génétiques avec les caractères de production. L'adaptation est ainsi prise en compte parmi les objectifs de sélection (Baker et Rege 1994). Cette approche nécessite de hiérarchiser les différents stress auxquels les animaux sont soumis en fonction de leur impact sur la productivité des troupeaux, de déterminer le stress le plus limitant et les meilleurs critères pour le sélectionner. Cette voie d'amélioration requiert en amont de nombreuses connaissances sur la variabilité du caractère et ses antagonismes génétiques éventuels avec les caractères de production.

Quand de telles connaissances ne sont pas disponibles car coûteuses, longues et/ou éthiquement difficiles à obtenir, la seconde voie d'amélioration génétique de l'adaptation est l'approche indirecte ou globale. L'effort de sélection se concentre alors uniquement sur les caractères de production dans le milieu contraignant et le potentiel adaptatif est amélioré indirectement. Cette voie est moins efficace que la précédente en particulier parce que les antagonismes génétiques entre production et adaptation sont négligés (Davis 1993). Cependant, du progrès génétique peut être obtenu (Poivey 1987). Ainsi, les lignées grand-parentales de poulet de chair sélectionnées en Inde ont une descendance plus productive en Inde que les lignées grand-parentales de la même origine installées en pays tempéré (Ansah 2000). Chez les ruminants, l'accent doit être porté sur les qualités maternelles (par exemple, fertilité, taille de portée optimale, valeur laitière des mères, longévité) comme c'est le cas en France dans les schémas d'amélioration des petits ruminants rustiques (Naves et al 2000b, 2001). Ces nouveaux critères peuvent être proposés aux sélectionneurs en milieu tropical quand des contrôles de performances fiables sont disponibles. Enfin, la sélection doit intervenir dans le milieu de production afin d'éviter les interactions génotype $x$ environnement très fréquentes en milieu contraignant (Menendez et Mandonnet 2006).

\section{b) Sélection et/ou croisement?}

Les programmes de croisement nécessitent le maintien des souches d'origine afin d'être reproductibles, et accompagnent le plus souvent des programmes de sélection sur les races parentales ou grand-parentales. Ainsi, ces deux voies ne sont pas antagonistes, mais bien complémentaires, et nécessitent le maintien de la biodiversité des ressources génétiques domestiques (FAO 2008).
Le croisement est déjà largement exploité par les firmes de sélection chez le porc et les volailles. L'alternative au croisement concerne essentiellement les ruminants. Pour les ruminants, une fois les objectifs et les critères de sélection bien définis, le progrès génétique peut être obtenu intra-race (locale ou exotique), par croisement ou par création d'une lignée synthétique. Plusieurs questions sont à considérer (Cunningham 1981, Le Gal et Planchenault 1993) : héritabilité des caractères d'intérêt dans la race locale ; productivité des animaux croisés ; choix de la meilleure race spécialisée et du protocole de croisement pour maximiser l'effet d'hétérosis.

Le choix d'une stratégie dépend ainsi de la quantité de connaissances génétiques disponibles sur la ou les race(s) locale(s) et du comportement de la race exotique en milieu difficile. Il n'est pas nécessaire d'avoir réponse à toutes ces questions avant d'agir. Cependant, en milieu difficile, la sélection intra-race locale est une stratégie appropriée quand l'environnement d'élevage ne peut être amélioré significativement et quand il est peu probable que les animaux croisés se comportent bien (Peacock 1996). Dans ce cas, l'accent doit être mis sur la sélection de la race locale sur des caractères de production tout en maintenant son niveau d'adaptation au milieu par la prise en compte de critères tels que la viabilité, ou d'autres critères plus analytiques. Cette option, à privilégier dans les petites populations locales, constitue un premier niveau d'amélioration nécessaire pour augmenter le niveau génétique de production jusque là non sélectionné. Dans un deuxième temps, des croisements terminaux peuvent être envisagés avec des mâles de races spécialisées dans les élevages les mieux conduits.

Par ailleurs, la sélection est un bon moyen d'amélioration pour des caractères simples, facilement mesurables, et moyennement à fortement héritables, comme c'est le cas pour les caractères de production (tels que la croissance et les qualités bouchères). En revanche, les caractères d'adaptation sont plus difficiles à caractériser, souvent complexes et peu héritables, et donc plus difficiles à améliorer. Ainsi, plus les contraintes environnementales sont importantes, plus il est efficace d'envisager la sélection d'animaux productifs au sein d'une race locale bien adaptée, plutôt que de rechercher des animaux adaptés dans une population spécialisée.

Enfin, certains auteurs considèrent qu'aucune organisation de sélection n'est viable en milieu tropical traditionnel et que le progrès génétique doit venir de l'extérieur via des reproducteurs de races spécialisées (Juvenal-Castillo et OmarGarcia 2001). Cette option est plus facile à mettre en œuvre mais sa durabilité est incertaine et ses résultats sont non mesurables en l'absence de contrôles de performances. Des expériences réussies ont été rapportées (amélioration du poids vif à 3 et 6 mois chez des chevreaux du Maharashtra en Inde grâce au croisement avec la race Boer, Nimbkar et al 2000) mais des échecs également (au Kenya, les chèvres East African et les Galla sont tolérantes à l'infection par Trypanosoma congolense tandis que les Saanen et leurs croisements en meurent (Griffin et Allonby 1979)). Chez le poulet, de nombreux programmes d'introduction de coqs améliorateurs n'ont pas été suivis d'effet, par manque d'organisation de la filière donnant lieu à des croisements non contrôlés, mais aussi par la perte de la capacité d'incubation naturelle des poules croisées en conditions villageoises.

L'enjeu du maintien et de la sélection de la race locale est modulé par la taille de cette population. En effet, en présence d'une population locale de petite taille et face aux risques d'absorption par des races importées, l'amélioration de celle-ci est primordiale (cas des chèvres Créole de Guadeloupe) pour sa conservation et celle des capacités d'adaptation qu'elle possède. Si la population locale est de grande taille (cas des bovins N'Dama en Afrique de l'Ouest), le risque d'absorption s'amenuise et l'amélioration par croisement avec des races spécialisées (sous réserve d'évaluer ces croisements) devient une voie plus rapide et souple que la sélection intra-race locale.

Les récents développements de la sélection génomique sont prometteurs car ils permettraient d'alléger les contrôles de performances et l'acquisition des pedigrees. Cependant, leur mise en œuvre nécessite des investissements et des structures de population (taille de population de référence) non encore disponibles dans la plupart des génotypes tropicaux.

c) Quelle organisation pratique mettre en place pour la diffusion du progrès génétique?

Afin de minimiser les interactions génotype $\times$ milieu, les sélectionneurs avicoles de dimension internationale ont installé des fermes de sélection de lignées grand-parentales en milieu chaud (Inde par exemple). La sélection avicole utilisant une combinaison de sélection intralignée pour les grand-parentales et de croisement pour la production des animaux terminaux, il est possible de jouer sur le choix des parentales à croiser en fonction du pays de production. 
Pour les ruminants, trois grandes organisations de la sélection peuvent être distinguées avec des niveaux croissants d'infrastructures et d'investissements financiers, plus ou moins adaptés aux milieux tropicaux : le troupeau élite (nucleus flock), les troupeaux commerciaux et les organisations au niveau national. Les troupeaux élites sont les schémas les plus flexibles. Le ou les partenaires s'entendent sur les objectifs du schéma et son organisation. Ils y contribuent en réservant leurs meilleures femelles au schéma et reçoivent en retour les meilleurs mâles améliorateurs. Le progrès génétique est lent du fait de la petite taille de la population base de sélection. Cette organisation opère comme une coopérative. Ce type de schéma est le plus souvent répandu dans les races locales, utilisant un centre d'élevage ou une station raciale. Le secteur commercial en zone tropicale est le plus souvent organisé en ranches périurbains (Lebbie et Ramsay 1999) dirigés par des compagnies privées ayant des capacités de financement. Ces compagnies ont un objectif commercial très marqué, et des gains financiers sont attendus grâce à l'utilisation et à la diffusion de ressources génétiques d'origine exotique, en race pure, race synthétique ou composite. A un niveau national ou institutionnel, des schémas d'amélioration efficaces peuvent être organisés, reposant sur un réseau d'exploitations constituant la base de sélection, encadrés par une organisation soutenue par les pouvoirs publics. Cependant, les infrastructures et investissements financiers font souvent défaut pour entreprendre des projets d'importance sur le long terme, en zone tropicale. L'amélioration génétique avec un troupeau élite est le plus souvent préconisée pour sa robustesse dans les environnements difficiles (Peacock 1996).

En zones tropicales et subtropicales, la durabilité des programmes d'amélioration génétique reste incertaine. Leur succès repose sur quatre éléments fondamentaux (Mandonnet 2010) :
- Leur durabilité sociale : les éleveurs doivent être associés dès le début de la mise en place du programme et à chaque étape, pour prendre en considération leur attachement à leur races locales et leurs souhaits sur l'évolution de leurs animaux. Dans le même temps, leurs connaissances vont augmenter ainsi que leur technicité.

- Leur durabilité biologique : le maximum doit être fait pour valoriser l'adaptation et les qualités maternelles des races locales.

- Leur durabilité technique : la fiabilité des pedigrees et des performances enregistrés doit être garantie par un suivi institutionnel, accompagné d'un soutien financier aux éleveurs pour améliorer leurs installations. Des critères de sélection aussi simples que possible doivent être choisis.

- Leur durabilité économique : une niche commerciale s'appuyant sur les qualités propres du produit doit être développée et promue afin qu'à terme, les éleveurs puissent vivre de leur activité indépendamment de toute subvention.

\section{Conclusion}

Ramsay et al (2000) ont résumé l'importance de l'adaptation des animaux dans ces termes «There is no universal breed». De la même façon, ils pourraient être paraphrasés en ces termes "There is no universal breeding system». Ainsi pour optimiser la productivité de l'élevage en zone tropicale et compenser les effets délétères des contraintes de l'environnement, le choix de conduites et de pratiques atténuant (ou prenant en compte) ces contraintes et du génotype (voire de l'espèce) le plus adapté, sont les deux leviers dont dispose 1'éleveur. Cela sous-tend la nécessité d'une réflexion multicritère sur les caractères d'adaptation pour pouvoir définir quel est le génotype le plus adapté. Après des décennies de standardisation et de message unique, le monde de l'élevage et la communauté scientifique prennent en compte de plus en plus la complexité des systèmes d'élevage et s'orientent vers l'intégration de ces diverses composantes (dont l'adaptation).

Cependant, la contribution des caractères d'adaptation à la productivité globale des troupeaux reste peu documentée. L'analyse de ces caractères doit être approfondie à la fois sur le plan conceptuel (modélisation d'allocation de ressources) et sur le plan expérimental (thermotolérance, alimentation, résistance aux maladies, comportement). De même, la caractérisation des populations animales indigènes reste insuffisante dans de nombreuses zones tropicales, et ce par manque de financement (Hoffmann 2010). En 2007, la FAO a identifié 7040 races locales (signalées dans un seul pays) et 1051 races transfrontières (signalées dans plusieurs pays). Deux tiers de ces races sont localisées dans les pays en voie de développement et restent mal caractérisées sur le plan phénotypique et génétique.

Enfin, il semble aussi évident qu'un des enjeux de recherche futur portera sur une meilleure compréhension des interactions génotype $\times$ milieu dans l'analyse des profils de réponses aux changements climatiques, la quantification de la plage de variation des réponses et l'identification des seuils de ruptures (Blanc et al 2004, 2010).

Du fait du réchauffement climatique, ces questionnements autour de l'amélioration de la résilience des systèmes d'élevages des milieux chauds vont se généraliser aux zones appelées aujourd'hui tempérées. L'adaptation des animaux aux systèmes d'élevage tropicaux pourraient ainsi servir de modèle d'étude de l'adaptation des animaux aux systèmes d'élevage tempérés en lien avec les évolutions probables de leur environnement écologique, économique et social (Archimède et Tillard 2009).

\section{Références}

Adakal H., Stachurski F., Konkobo M., Zoungrana S., Meyer D.F., Pinarello V., Aprelon R., Marcelino I., Alves P.M., Martinez D., Lefrancois T., Vachiéry N., 2010. Efficiency of inactivated vaccines against heartwater in Burkina-Faso: Impact of Ehrlichia ruminantium genetic diversity. Vaccine, 28, 4573-4580.

Ain Baziz H., Geraert P.A., Padilha J.C., Guillaumin S., 1996. Chronic heat exposure enhances fat deposition and modifies muscle and fat partition in broiler carcasses. Poult. Sci., 75, 505-513.
Albers G.A.A., Gray G.D., Piper L.R., Barker J.S.F., Le Jambre L.F., Barger I.A., 1987. The genetics of resistance and resilience to Haemonchus contortus infection in young Merino sheep. Int. J. Parasitol., 17, 1355-1363.

Alexandre G., Mandonnet N., 2005. Goat meat production in harsh environments. Small Rum. Res., 60, 53-66.

d'Alexis S., Loranger-Merciris G., Mahieu M. Boval M., 2009. Influence of earthworms on development of the free-living stages of gastrointestinal nematodes in goat faeces. Vet. Parasitol., 163, 171-174.

Ansah G.A., 2000. Matching genetic potential for performance with field conditions: the layer industry worldwide. XXI World's Poult. Congr., Montreal, Canada, August 20-24, Abstracts and Proceedings. World's Poult. Sci. Ass., 1-12.

Arad Z., Marder J., 1983. Acid-base regulation during thermal panting in the fowl (Gallus domesticus): Comparison between breeds. Comp. Biochem. Physiol., Part A Physiology, 74, 125-130. 
Araujo R.N., Padilha T., Zarlenga D., Sonstegard T., Connor E.E., Van Tassell C., Lima W.S., Nascimento E., Gasbarre L.C., 2009. Use of a candidate gene array to delineate gene expression patterns in cattle selected for resistance or susceptibility to intestinal nematodes. Vet. Parasitol., 162, 106-115.

Archimède H., Tillard E., 2009. Ressources végétales et animales : capacités d'adaptation aux contraintes. In : Enjeux et priorités de la Recherche pour l'élevage dans les pays des Sud. Session satellite, Renc. Rech. Rum., 21-31.

Atti N., Bocquier F., 1999. Adaptation des brebis Barbarine à l'alternance sous-nutritionréalimentation : effets sur les tissus adipeux. Ann. Zootech., 48, 189-198.

Atti N., Nozière P., Doreau M., Kayouli C., Bocquier F., 2000. Effects of underfeeding and refeeding on offals weight in the Barbary ewes. Small Rum. Res., 38, 37-43.

Atti N., Kayouli C., Mahouachi M., Guesmi A., Doreau M., 2002. Effect of a drastic and extended underfeeding on digestion in Barbary ewe. Anim. Feed Sci. Technol., 100, 1-14.

Atti N., Bocquier F., Khaldi G., 2004. Performance of the fat-tailed Barbarine sheep in its environment: adaptive capacity to alternation of underfeeding and re-feeding periods. A review. Anim. Res., 53, 165-176.

Aumont G., Gauthier D., Coulaud G., Gruner L., 1991. Gastrointestinal parasitism of cattle in native pasture grazing system in Guadeloupe (French West Indies). Vet. Parasitol., 40, 29-46.

Azoulay Y., Druyan S., Yadgary L., Hadad Y., Cahaner A., 2011. The viability and performance under hot conditions of featherless broilers versus fully feathered broilers. Poult. Sci., 90,19-29.

Bailey D.W., Dumont B., Wallis DeVries M.F., 1998. Utilization of heterogeneous grasslands by domestic herbivores: theory to management. Ann. Zootech., 47, 321-333.

Baker R.L., Rege J.E.O., 1994. Genetic resistance to diseases and other stresses in improvement of ruminant livestock in the tropics. $5^{\text {th }}$ World Congr. Genet. Appl. Livest. Prod., Guelph, Canada, 20, 405-412.

Baker R.L., Gray G.D., 2003. Appropriate breeds and breeding schemes for sheep and goats in the tropics. Worm control for tropical Asia. Sani R.A., Gray G.D., Baker R.L. (Eds). ACIAR, 272p.

Baker R.L., Mwamachi D.M., Audho J.O., Aduda E.O., Thorpe W., 1998. Resistance of Galla and small East African goats in the subhumid tropics to gastrointestinal nematode infections and the peri-parturient rise in faecal egg counts. Vet. Parasitol., 79, 53-64.

Bambou J.C., de la Chevrotière C., Varo H., Arquet R., Kooyman F.N.J., Mandonnet N., 2008. Serum antibody responses in Creole kids experimentally infected with Haemonchus contortus. Vet. Parasitol., 158, 311-318.

Bambou J.C., Gonzalez-Garcia E., de la Chevrotière C., Arquet R., Vachiery N., Mandonnet N., 2009. Peripheral immune response in resistant and susceptible Creole kids experimentally infected with Haemonchus contortus. Small Rum. Res., 82, 34-39.

Bambou J.C., de la Chevrotière C., Gunia M., Arquet R., Mandonnet N., 2010a. High genetic correlation between resistance to strongyle natural mixed infection and resistance to
Haemonchus contortus experimental infection in Creole goats. $X^{\text {th }}$ Int. Conf. Goats in Recife, Brasil, September 19-23 ${ }^{\text {rd, }}$ Recif, Brésil.

Bambou J.C., Vachiery N., Despois P., Giraud-Girard K., Arquet R., Pinarello V., Aprelon R., Barbier C., Gobardham J., Mandonnet N., Lefrancois T., $2010 \mathrm{~b}$. Assessment of genetic variability of resistance to heartwater in Creole goats. Sustainable Animal Production for Tropics Congress, Gosier, Guadeloupe-FWI, 15-17 November, Adv. Anim. Biosci., 1, 408.

Barré N., 1997. Les tiques des ruminants dans les Petites Antilles : biologie, importance économique, principes de lutte. INRA Prod. Anim., 10, 111-119.

Barré N., Woodman S., 1990. Dermatophilosis. Adv. Vet. Dermatol., 1, 407-417.

De Basilio V., Vilariño M., Yahav S., Picard M., 2001. Early age thermal conditioning and a dual feeding program for male broilers challenged by heat stress. Poult. Sci., 80, 29-36.

Bath G.F., Malan F.S. Van Wyk J.A., 1996. The FAMACHA ovine anaemia guide to assist with the control of haemonchosis. $7^{\text {th }}$ Ann. Congr. Livest. Health Production Group South African Vet. Ass., 152-156.

Baumont R., Prache S., Meuret M., MorandFehr P., 2000. How forage characteristics influence behaviour and intake in small ruminants: a review. Livest. Prod. Sci., 64, 15-28.

Baumont R., Cohen-Salmon D., Prache S., Sauvant D., 2004. A mechanistic model of intake and grazing behaviour in sheep integrating sward architecture and animal decisions. Anim. Feed Sci. Technol., 112, 5-28.

Bengoumi M., Faye B., 2002. Adaptation du dromadaire à la déshydratation. Rev. Sécheresse, 13, 121-129.

Bengoumi M., Tabarani A., Sghiri A., Faulconnier Y., Faye B., Chilliard Y., 2005. Effects of overfeeding and underfeeding on body weight, lipid content and cellularity in the dromedary camel. Anim. Res., 54, 383-393.

Berbigier P., 1988. Bioclimatologie des ruminants domestiques en zone tropicale. INRA Editions, Versailles, France, 237p.

Besier R.B., 2005. Electronic sheep hadling technology for targeted treatment of Trichostrongylus and Ostertagia in Australia. $4^{\text {th }}$ Int. Workshop, Novel Approaches to the Control of Helminth Parasites of Livestock, 16.

Bhayani D.M., Vyas K.N., 1990. Regional differences in the sweat gland characteristics in Gir cattle with reference to thermoregulation. Ind. J. Anim. Sci., 60, 817-820.

Biquand S., Biquand-Guyot V., 1991. Etude du pâturage mixte caprins, bovins en Martinique. Rev. Elev. Méd. Vét. Pays Trop., 44, spécial, 23-26.

Bishop S.C. Morris C.A., 2007. Genetics of disease resistance in sheep and goats. Small Rum. Res., 70, 48-59.

Blanc F., Bocquier F., Debus N., Agabriel J., D'Hour P., Chillard Y., 2004. La pérennité et la durabilité des élevages de ruminants dépendent des capacités adaptatives des femelles. INRA Prod. Anim., 17, 287-302.

Blanc F., Dumont B., Brunschwig G., Bocquier F., Agabriel J., 2010. Robustesse, flexibilité, plasticité : des processus adaptatifs révélés dans les systèmes d'élevage extensifs de ruminants. In : Robustesse, rusticité, flexibilité, plasticité, résilience... les nouveaux critères de qualité des animaux et des systèmes d'élevage. Sauvant D., Perez J.M. (Eds). Dossier, INRA Prod. Anim., 23, 65-80.

Bolormaa S., Van Der Werf J.H.J., WalkdenBrown S.W., Marshall K., Ruvinsky A., 2010. A quantitative trait locus for faecal worm egg and blood eosinophil counts on chromosome 23 in Australian goats. J. Anim. Breed. Genet., 127, 207-214.

Bordas A., Merat P., 1984. Effects of the naked-neck gene on traits associated with egg laying in a dwarf stock at two temperatures. Brit. Poult. Sci., 25, 195-207.

Bordas A., Minvielle F., 1997. Effects of temperature on egg laying hens from divergent lines selected on residual feed consumption. Genet. Sel. Evol., 29, 279-290.

Borges S.A., Fischer da Silva A.V., Majorka A., Hooge D.M., Cummings K.R., 2004. Physiological responses of broiler chickens to heat stress and dietary electrolyte balance (sodium plus potassium minus chloride, milliequivalents per kilogram). Poult. Sci., 83, 1551-1558.

Boussaid-Om Ezzine S., Everaert N., Métayer-Coustard S., Rideau N., Berri C., Joubert R., Temim S., Collin A., Tesseraud S., 2010. Effects of chronic heat exposure on insulin signaling and expression of genes related to protein and energy metabolism in chicken (Gallus gallus) pectoralis major muscle. Comp. Biochem. Physiol., Part B Biochem. Mol. Biol., 157, 281-287.

Brosh A., Shkolnik A., Choshniak I., 1987. Effect of infrequent drinking of the nitrogen metabolism of Bedouin goats maintained on different diets. J. Agric. Sci., 109, 165-169.

Brosh A., Aharoni Y., Degen A.A., Wright D., Young B.A., 1998. Effects of solar radiation, dietary energy and time of feeding on thermoregulatory responses and energy balance in cattle in a hot environment. J. Anim. Sci., 76, 2671-2677.

Broughan J.M., Wall R., 2007. Faecal soiling and gastrointestinal helminth infection in lambs. Int. J. Parasitol., 37, 1255-1268.

Burrow H.M., 2006. Utilization of diverse breed resources for tropical beef production. $8^{\text {th }}$ World Congr. Appl. Livest. Prod., August 13-18, Belo Horizonte, MG, Brasil, 32-01.

Cahaner A., Leenstra F., 1992. Effects of high-temperature on growth and efficiency of male and female broilers from lines selected for high weight-gain, favourable feed conversion, and high or low fat-content. Poult. Sci., $71,1237-1250$.

Cahaner A., Tzur N., 2010. Featherless broilers may lower the costs and the environmental impact of poultry meat production under hot conditions. $9^{\text {th }}$ World Congr. Appl. Livest. Prod., August 1-6, Leipzig, Germany, 0781.

Cahaner A., Ajuh J.A. Siegmund-Schultze M., Azoulay Y., Druyan S., Zarate A.V., 2008. Effects of the genetically reduced feather coverage in naked neck and featherless broilers on their performance under hot conditions. Poult. Sci., 87, 2517-2527.

Cavestany D., Blanc J.E., Kulcsar M., Uriarte G., Chilibroste P., Meikle A., Febel H., Ferraris A., Krall E., 1985. Studies of the transition cow under a pasture-based milk production system: metabolic profiles. J. Vet. Med. Series, 52, 1-7. 
Chandrawathani P., Jamnah O., Waller P.J., Hoglund J., Larsen M., Zahari W.M., 2002. Nematophagous fungi as a biological control agent for nematode parasites of small ruminants in Malaysia: a special emphasis on Duddingtonia flagrans. Vet. Res., 33, 685-696.

De La Chevrotière C., Bambou J.C., Arquet R., Jaquot M., Mandonnet N., 2009a. Apport des outils de la sélection à la maitrise des strongyloses gastro-intestinales des petits ruminants : cas particulier de la chèvre Créole de Guadeloupe. Renc. Rech. Rum., 16, 269-272.

De la Chevrotière C., Bishop S., Moreno C., Arquet R., Bambou J.C., Schibler L., Amigues Y., Mandonnet N., 2009b. Identification of QTL associated with gastrointestinal nematode resistance in Creole goat. $60^{\text {th }}$ Ann. Meeting, 24-27 August, Barcelona, Spain, EAAP, Anim. Genet. Free Comm., S 53.

Chilliard Y., Bocquier F., Doreau M., 1998. Digestive and metabolic adaptions of ruminants to undernutrition, and consequences on reproduction. Reprod. Nutr. Dev., 38, 131-152.

Chilliard Y., Delavaud C., Bonnet M., 2004 Leptin expression in ruminants: Nutritional and physiological regulations in relation with energy metabolism. Dom. Anim. Endocrinol., 29, 3-22.

Chirat G., Ickowicz A., Diaf H., Bocquier F. 2009. Etude des facteurs clés du comportement spatial et alimentaire de troupeaux bovins en libre pâture sur un territoire «agrosylvopastoral» tropical. Renc. Rech. Rum., 16, 327-330.

Collin A., Lebreton Y., Fillaut M., Vincent A., Thomas F., Herpin P., 2001a. Effects of exposure to high temperature and feeding level on regional blood flow and oxidative capacity of tissues of piglets. Exp. Physiol., 86, 83-91.

Collin A., Van Milgen J., Dubois S., Noblet J., 2001b. Effect of high temperature and feeding level on energy utilization in piglets. J. Anim. Sci., 79, 1849-1857.

Collin A., Van Milgen J., Dubois S., Noblet J., 2001c. Effect of high temperature on feeding behaviour and heat production in grouphoused young pigs. Brit. J. Nutr., 86, 63-70.

Collin A., Picard M., Yahav S., 2005. The effect of duration of thermal manipulation during broiler chick's embryogenesis on body weight and body temperature of post hatched chicks. Anim. Res., 54, 105-112.

Collin A., Berri C., Tesseraud S., Rodón F.E., Skiba-Cassy S., Crochet S., Duclos M.J., Rideau N., Tona K., Buyse J., Bruggeman V., Decuypere E., Picard M., Yahav S., 2007. Effects of thermal manipulation during early and late embryogenesis on thermotolerance and breast muscle characteristics in broiler chickens. Poult. Sci., 86, 795-800.

Comito R.W., Reece W.O., Trampel D.W., Koehler K.J., 2007. Acid-base balance of the domestic turkey during thermal panting. Poult. Sci., 86, 2649-2652.

Coppieters W., Mes T.H.M., Druet T., Fanir F., Tamma N., Schrooten C., Cornelissen A.W.C.A., Georges M., Ploeger H.W., 2009. Mapping QTL influencing gastrointestinal nematode burden in Dutch Holstein-Friesian dairy cattle. BMC Genomics, 10, 96.

Coulon J.B., 1984a. Comportement alimentaire de bovins croisés Charolais en milieu tropical humide. Rev. Elev. Méd. Vét. Pays Trop., 37, $185-190$
Coulon J.B., 1984b. Consommation d'eau de boisson par des bovins d'origine européenne en milieu tropical humide. Rev. Elev. Méd. Vét. Pays Trop., 37, 191-196.

Crawford A.M., Paterson K.A., Dodds K.G., Diez Tascon C., Williamson P.A., Roberts Thompson M., Bisset S.A., Beattie A.E., Gree G.J., Green R.S., Wheeler R., Shaw R.J. Knowler K., McEwan J.C., 2006. Discovery of quantitative trait loci for resistance to parasitic nematode infection in sheep: 1 Analysis of outcross pedigrees. BMC Genomics 7, 178

Cunnigham E.P., 1981. Selection and crossbreeding strategies in adverse environments in animal genetic resources conservation and management. FAO Rome, Italie. FAO Production and Health, Paper 24, 279-287.

Dale N.M., Fuller H.L., 1980. Effect of diet composition on feed intake and growth of chicks under heat stress. II. Constant vs cycling temperatures. Poult. Sci., 59, 14341441

Danchin-Burge C., Palhière I., François D., Bibé B., Leroy G., Verrier E., 2010. Pedigree analysis of seven small French sheep populations and implications for the management of rare breeds. J. Anim. Sci., 88, 505-516.

Daramola J.O., Adeloye A.A., 2009. Physiological adaptation to the humid tropics with special reference to the West African Dwarf (WAD) goat. Trop. Anim. Health Prod., 41, 1005-1016.

Dauncey M.J., Ingram D.L., 1986. Acclimatization to warm or cold temperatures and the role of food intake., J. Theor. Biol., 11, 89-93.

Davis G.P., 1993. Genetic parameters for tropical beef cattle in northern Australia: a review. Aust. J. Agric. Res., 44, 179-198.

Dayo G.K., Thevenon S., Berthier D., Moazami-Goudarzi K., Denis C., Cuny G. Eggen A., Gautier M., 2009. Detection of selection signatures within candidate regions underlying trypanotolerance in outbred cattle populations. Mol. Ecol., 18, 1801-1813.

Deaton J.W., 1983. Alleviation of heat stress for avian egg production. A review. World's Poult. Sci. J., 39, 210-217.

Dedieu B., Ingrand S., 2010. Incertitudes et adaptation : cadres théoriques et application à l'analyse de la dynamique des systèmes d'élevage. In : Robustesse, rusticité, flexibilité plasticité, résilience... les nouveaux critères de qualité des animaux et des systèmes d'élevage. Sauvant D., Perez J.M. (Eds). Dossier, INRA Prod. Anim., 23, 81-90.

Delagarde R., Perez-Ramirez E., Delaby L., Peyraud J.L., 2008. Adaptation comportementale et ingestion des vaches laitières soumises à une restriction du temps d'accès journalier au pâturage. Renc. Rech. Rum., 15, 323-326.

Demment W., Van Soest P.J., 1985. A nutritional explanation for body-size patterns of ruminant and nonruminant herbivores. Am. Soc. Nat., 125, 641-672.

Doreau M., Grimaud P., Michalet-Doreau B, 2000. La sous-alimentation chez les ruminants : ses effets sur la digestion. INRA Prod. Anim., 13, 247-255.

Dulphy J.P., Balch C.C., Doreau M., 1995. Adaptation des espèces domestiques à la digestion des aliments lignocellulosiques. In Nutrition des ruminants domestiques : ingestion et digestion. Jarrige P., Ruckebusch Y.,
Demarquilly C., Farce M.H., Journet M. (Eds) INRA, Paris, France, 1, 759-803.

Emmanuel B., 1980. Oxidation of butyrate to ketone bodies and $\mathrm{CO}_{2}$ in the rumen epithelium, liver, kidney and lung of camel (Camelus dromedarius), sheep (Ovis aries) and goat (Capra hircus). Comp. Biochem. Physiol., 65B, 699-704.

Epstein H., 1971. The origin of the domestic animals of Africa, Leipzig, Germany, 2, 585629

Esteves I., Vachiery N., Martinez D., Totté P., 2004, Analysis of Ehrlichia ruminantiumspecific T1/T2 responses during vaccination with a protective killed vaccine and challenge of goats. Parasite Immunol., 26, 95-103.

Etzion Z., Alfassi Z., Lavi N., Yagil R., 1987. Halide concentration in camel plasma in various state of dehydration. Biol. Trace Elem. Res., 12, 411-418.

Ezanno P., Ickowicz A., Lancelot R., 2005. Relationships between N'Dama cow body condition score and production performance under an extensive range management system in Southern Senegal: calf weight gain, milk production, probability of pregnancy, and juvenile mortality. Livest. Prod. Sci., 92, 291-306.

Fabiyi J.P., 1987. Production losses and control of helminths in ruminants of tropical regions. Int. J. Parasitol., 17, 435-442.

FAO, 2008. L'état des ressources zoogénétiques pour l'alimentation et l'agriculture dans le monde, édité par Barbara Rischkowsky et Dafydd Pilling. Rome, Italie, 551p.

Faye B., Tisserand J.L., 1989. Problèmes de la détermination de la valeur alimentaire des fourrages prélevés par le dromadaire. Séminaire sur la nutrition et l'alimentation du dromadaire, Ouargla, Algérie. Options Méd., 2, 61-65.

Faye B., Bengoumi M., Messad S., Chilliard Y, 2002. Estimation des réserves corporelles chez le dromadaire. Rev. Elev. Méd. Vét. Pays Trop., 55, 69-78.

Ferreira F., Campos W.E., Carvalho A.U, Pires M. F.A., Martinez M.L., Silva M.V.GB. Verneque R.S., Silva P.F., 2009. Sweat rate and histological parameters of cattle submitted to heat stress. Arquivo Bras .Med. Vet. Zootec., 61, 763-768.

Figueiredo E.A.P., Blackburn H.D., Sanders J.O., Cartwright T.C., Shelton J.M., 1989. Potential genotypes for Moranda Nova sheep in northeastern Brazil. J. Anim. Sci., 67, 19561963.

Franklin I.R., 1986. Breeding ruminants for the tropics. Proc. $3^{\text {rd }}$ WCGALP, Lincoln, Nebraska, USA, July 16-22. Breeding programs for dairy and beef cattle, water buffalo, sheep and goats, IX, 451-461.

Garcia F., Carrère P., Soussana J.F., Baumont R., 2003. The ability of sheep at different stocking rates to maintain the quality and quantity of their diet during the grazing season. J. Agric. Sci., 140, 113-124.

Gasparin G., Miyata M., Coutinho L.L., Martinez M.L., Teodoro R.L., Furlong J., Machado M.A., Silva M.V.G.B., Sonstegard T.S., Regitano L.C.A., 2007. Mapping of quantitative trait loci controlling tick [Riphicephalus (Boophilus) microplus] resistance on bovine chromosomes 5, 7 and 14 . Anim. Genet., 38, 453-459. 
Gauly M., Besbes B., Pinard-van der Laan M.H., Hoffmann I., Greef J., Thevenon S., Baker L., Tibbo M., Bishop S.C., Mugambi J., Dempfle L., Sidibe I., Mandonnet N., Amarande A.F.T., Miller J.E., 2010. Ruminant genetic resources and their resistance/tolerance to parasitic diseases. $9^{\text {th }}$ World Congr. Genet. Appl. Livest. Prod., August 1-6, Leipzig, Germany, 0445.

Gauthier D., Thimonier J., 1985. Variations saisonnières de la durée de l'inactivité ovulatoire post-partum et de la fertilité des vaches Françaises Frisonnes Pie Noires élevées en Guadeloupe. Ann. Zootech., 34, 347-354.

Gauthier D., Aumont G., Barre N., Berbigier P., Camus E., Lafortune E., Popescu P., Rulquin H., Xande A., Thimonier J., 1984. Le bovin créole en Guadeloupe : caractéristiques et performances zootechniques. Rev. Elev. Méd. Vét. Pays Trop., 37, 212-224.

Gautier M., Flori L., Riebler A., Jaffrézic F., Laloé D. Gut I., Moazami-Goudarzi K. Foulley J.L., 2009. A whole genome Bayesian scan for adaptive genetic divergence in West African cattle. BMC Genomics, 10, 550.

Geraert P.A., Guillaumin S., Leclercq B., 1993. Are genetically lean broilers more resistant to hot climate? Brit. Poult. Sci., 34, 643-653.

Geraert P.A., Padilha J.C., Guillaumin S., 1996. Metabolic and endocrine changes induced by chronic heat exposure in broiler chickens: growth performance, body composition and energy retention. Brit. J. Nutr., 75, 195-204.

Gill H.S., Altmann K., Cross M.L., Husband A.J., 2000. Induction of T helper 1- and T helper 2-type immune responses during Haemonchus contortus infection in sheep. Immunology, 99, 458-463.

Gourdine J.L., Mandonnet N., Naves M., Bidanel J.P., Renaudeau D., 2006. Genetic parameters of rectal temperature in sows in a tropical humid climate and its association with performance during lactation: preliminary results. $8^{\text {th }}$ World Congr. Genet. Appl. Livest. Prod., Belo Horizonte, Brasil, 16-29.

Gourdine J.L., Bidanel J.P., MenendezBuxadera A., Mandonnet N., Naves M., Renaudeau D., 2007. Estimation des relations génétiques de la température rectale chez la truie en lactation en relation avec les performances. Journ. Rech. Porcine Fr., 39, 293-294.

Gowe R.S., Fairfull R.W., 1995. Breeding for resistance to heat stress. In: Poultry production in hot climates. Daghir N.J. (Ed). 1-29.

Gregorio Rosales A., 1994 Managing stress in broiler breeders: a review. J Appl. Poult Res., 3, 199-207.

Grimard B., Sauvant D., Chilliard Y., 2002. Les relations nutrition-reproduction dans l'espèce bovine. INA Paris Grignon, Association Française de Zootechnie, Paris, France, 1-18.

Grimaud P., Richard D., Vergeron M.P., Guilleret J.R., Doreau M., 1999. Effect of drastic undernutrition on digestion in zebu cattle receiving a diet based on rice straw. J. Dairy Sci., 82, 974-981.

Griffin L., Allonby E.W., 1979. Trypanotolerance in breeds of sheep and goats with an experimental infection of Trypanosoma congolense. Vet. Parasitol., 5, 97-105.

Groeneveld L.F., Lenstra J.A., Eding H., Toro M.A., Scherf B., Pilling D., Negrini R.,
Finlay E.K., Jianlin H., Groeneveld E. Weigend S., The GLOBALDIV Consortium, 2010. Genetic diversity in farm animals. A review. Anim. Genet., 41 (Suppl. 1), 6-31.

Gruner L., Bouix J., Brunel J.C., 2004. High genetic correlation between resistance to Haemonchus contortus and to Trichostrongylus colubriformis in INRA 401 sheep. Vet Parasitol., 119, 51-58.

Gunia M., Mandonnet N., Arquet R., de la Chevrotière C., Naves M., Mahieu M., Alexandre G., 2010a. Production systems of Creole goat and their implications for a breeding programme. Animal, 4, 2099-2105.

Gunia M., Phocas F., de la Chevrotière C., Bambou J.C., Mandonnet N., 2010b. Genetic parameters of resistance and growth traits for a breeding programme in Creole goats. $9^{\text {th }}$ World Congr. Genet. Appl. Livest. Prod., August 1-6, Leipzig, Germany, 0378, A4-140.

Hammond A.C., Olson T.A., 1994. Rectal temperature and grazing time in selected beef cattle breeds under tropical summer conditions in subtropical Florida. Trop. Agric., 71, 128134

Hanotte O., Ronin Y., Agaba M., Nilsson P., Gelhaus A., Horstmann R., Sugimoto Y., Kemp S., Gibson J., Korol A., Soller M., Teale A., 2003. Mapping of quantitative trait loci controlling trypanotolerance in a cross of toleran West African N'Dama and susceptible East African Boran cattle. Proc. Nat. Acad. Sci. USA, 100, 7443-7448.

Hayes B.J., Bowman P.J., Chamberlain A.J., Savin K., van Tassell C.P., Sonstegard T.S. Goddard M.E., 2009. A validated genome wide association study to breed cattle adapted to an environment altered by climate change. Plos One, 4(8), doi:10.1371/journal.pone.0006676

Hoffmann I., 2010. Climate change and the characterization, breeding and conservation of animal genetic resources. Anim. Genet., 41, 32-46.

Hofmann R.R., 1989. Evolutionary steps of ecophysiological adaptation and diversification of ruminants: a comparative view of their digestive system. Oecologia, 78, 443-457.

Houdijk J.G.M., 2008. Influence of periparturient nutritional demand on resistance to parasites in livestock. Parasite Immunol., 30, 113-121.

Houdijk J.G.M., Kyriazakis I., Jackson F., Coop R.L., 2001b. The expression of immunity to Teladorsagia circumcincta in ewes and its relationship to protein nutrition depend on body protein reserves. Parasitology, 122, 661-672.

Houdijk J.G.M., Kyriazakis I., Jackson F., Huntley J.F. Coop R.L., 2005. Effects of protein supply and reproductive status on local and systemic immune responses to Teladorsagia circumcincta in sheep. Vet. Parasitol., 129, 105-117.

Hummel J., Steuer P., Südekum K.H., Hammer S., Hammer C., Streich W.J., Clauss M., 2008. Fluid and particle retention in the digestive tract of the addax antelope (Addax nasomaculatus). Adaptations of a grazing desert ruminant. Comp. Biochem. Physiol., Part A, Molecular Integrative Physiology, 149, 142-149.

Ingham A., Reverter A., Windon R., Hunt P. Menzies M., 2008. Gastrointestinal nematode challenge induces some conserved gene expression changes in the gut mucosa of genetically resistant sheep. Int. J. Parasitol., 38, 431-442.
Jeon J.H., Yeon S.C., Choic Y.H., Minc W., Kimc S., Kima P.J., Chang H.H., 2006. Effects of chilled drinking water on the performance of lactating sows and their litters during high ambient temperatures under farm conditions. Livest. Sci., 105, 86-93.

Jordan A., 1992. Situation et conditions de développement du secteur productif au sein d'une filière laitière en milieu tropical insulaire : le cas des Antilles françaises. Thèse, INA Paris Grignon, ENSSAA, INRA. Centre de Recherche Agronomique des Antilles-Guyane, $192 \mathrm{p}$

Jouany J.P., 2000. La digestion chez les camélidés ; comparaison avec les ruminants. INRA Prod. Anim., 13, 165-176.

Juvenal-Castillo M., Omar-Garcia B., 2001. Las zonas secas, los sistemas de producción y el mejoramiento genético en el contexto de la ganadería caprina y sus persepctivas en Venezuela. 16 Réunión sobre Caprinocultura, 17-19 octubre, Puerto de Veracruz, México.

Kadzere C.T., Murphy M.R., Silanikove N., Maltz E., 2002. Heat stress in lactating dairy cows: a review, Livest. Prod. Sci., 77, 59-91.

Kaufmann F., Das G., Preisinger R., König S., Gauly M., 2010. Genetic resistance to natural helminth infections in two chicken layer lines. 9th World Congr. Genet. Appl. Livest. Prod., August 1-6, Leipzig, Germany, 337.

King J.M., 1989. Influence du climat et de l'alimentation sur les besoins en eau du bétail en Afrique tropical. CIPEA, Addis-Abeba, 7, $103 p$.

Kongsuwan K., Piper E.K., Bagnall N.H., Ryan K., Moolhuijzen P., Bellgard M., Lew A., Jackson L., Jonsson N.N., Pinard M.H., Gay C., Pastoret P.P., 2008. Identification of genes involved with tick infestation in Bos taurus and Bos indicus. In: Animal genomics for animal health. Pinard M.H., Gay C., Pastoret P.P., Dodet B. (Eds). Dev. Biol., 132, 77-88.

Laganá C., Machado Leal Ribeiro A., Diaz González F H., de Almeida Lacerda L., Ribeiro Kratz L., Rick Barbosa P., 2007. Dietary levels of protein and fat on biochemical and hematological parameters and on feathering in heat stressed broilers. Riv. Bras. Zootec., 36, $1783-1790$

Landau S., Provenza F., Silanikove N., 2000. Feeding behavior and utilization of vegetation by goats in extensive systems. $7^{\text {th }}$ Int. Conf. Goats, INRA, Institut de l'élevage, International Goat Association, Tours-Poitiers, France, 47-52.

Langbein J., Nichelmann M., 1993. Differences in behaviour of free-ranging cattle in the tropical climate. Appl. Anim. Behav. Sci., 37, 197-209.

Lebbie S.H.B., Ramsay K., 1999. A perspective on conservation and management of small ruminant genetic resources in the sub-Saharan Africa. Small Rum. Res., 34, 231-247.

Le Bellego L., van Milgen J., Noblet J., 2001. Effect of high temperature and energy intake on energy utilization in growing pigs. J. Anim. Sci., 79 (Suppl. 1), 211.

Le Gal O., Planchenault D., 1993. Utilisation des races caprines exotiques dans les zones chaudes. Contraintes et intérêts. Le Gal O., Planchenault D. (Eds). CIRAD-EMVT, 261p.

Leterrier C., Colina Y., Collin A., Bastianelli D., Constantin P., De Basilio V., 2009. Effets d'élevations tardives de la température ambiante 
sur la température corporelle et l'hyperventilation chez le poulet. 8 èmes Journ. Rech. Avicole, 25-26 mars, St-Malo, France, 34

Mahieu M., Aumont G., Michaux Y., Alexandre G., Archimède H., Boval M. Theriez M., 1997. L'association d'ovins et de bovins sur prairies irriguées en Martinique. INRA Prod. Anim., 10, 55-65.

Mahieu M., Arquet R., Kandassamy T. Mandonnet N., Hoste H., 2007. Evaluation of targeted drenching using Famacha $\odot$ method in Creole goat: Reduction of anthelmintic use, and effects on kid production and pasture contamination. Vet. Parasitol., 146, 135-147.

Mahieu M., Arquet R., Fleury J., Coppry O., Marie-Magdeleine C., Boval M., Archimède H., Alexandre G., Bambou J.C., Mandonnet N., 2009. Contrôle intégré du parasitisme gastrointestinal des petits ruminants au pâturage en zone tropicale humide. Renc. Rech. Rum., 16 , 265-268.

Maillard J.C., Chantal I., Berthier D., Stachursky F., Elsen J.M., 1999. Molecular markers of genetic resistance and susceptibility to bovine dermatophilis. Arch. Tierz., 42, 93-96.

Makkar H.P.S., 2003. Effects and fate of tannins in ruminant animals, adaptation to tannins, and strategies to overcome detrimental effects of feeding tannin-rich feeds. Small Rum. Res., $49,241-256$

Maloiy G.M.O., 1972. Renal salt and water excretion in the Camel (Camelus dromedarius). Symp. Zool. Soc. Lond., 31, 243-259.

Mandonnet N., 2009. Adaptation des populations animales aux systèmes d'élevage tropicaux : Analyser la variabilité génétique en vue de sélectionner et de comprendre les gènes et mécanismes impliqués. Rapport HDR Université Antilles-Guyane, 45p.

Mandonnet N., 2010. Integration of tolerance to gastrointestinal (GI) nematodes into a Creole goat breeding program in Guadeloupe: An application of developed country research in developing animal production systems. Proc. Anim. Genet. Resources and their resistance/tolerance to diseases, with special focus on parasitic diseases in ruminants. Gauly M., Besbes B., Baker L. (Eds). Joint FAO/INRA Workshop held at Jouy-en-Josas, 22-23 June Paris, France, 59-63.

Mandonnet N., Menendez-Buxadera A., Arquet R., Mahieu M., Bachand M., Aumont G., 2006. Genetic variability in resistance to gastrointestinal strongyles during early lactation in Creole goats. Anim. Sci., 82, 283-287.

Marie-Magdeleine C., Mahieu M., Philibert L., Despois P., Archimède H., 2009. Effect of cassava (Manihot esculenta crantz) foliage on nutrition, parasite infection and growth of lambs. Small Rum. Res., 93, 10-18.

Martinez M.L., Machado M.A., Nascimento C.S., Silva M.V.G.B., Teodoro R.L., Furlong J., Prata M.C.A., Campos A.L., Azevedo A.L.S., Pires M.F.A., Verneque R.S., 2006. Association of BoLA-DRB3.2 alleles with tick (Boophilus microplus) resistance in cattle. Genet. Mol. Res., 5, 513-524.

McGlone J.J., Stansbury W.F., Tribble L.F., 1988. Management of lactating sows during heat stress: Effects of water drip, snout coolers, floor type and a high energy-density diet. J. Anim. Sci., 66, 885-891.

Menendez-Buxadera A., Mandonnet N. 2006. The importance of the genotype $x$ envi- ronment interaction for selection and breeding programmes in tropical conditions. $\mathrm{CAB}$ Reviews, 26.

Mérat P., 1986. Potential usefulness of the $\mathrm{Na}$ (Naked Neck) gene in poultry production, World's Poult. Sci. J., 42, 124-142.

Mérat P., Bordas A., 1982. Etude des particularités de la poule Fayoumi. I. Performances de ponte en cages individuelles à deux températures. Ann. Génét. Sél. Anim., 14, 241-244.

Mérat P., Bordas A., Coquerelle G., 1979. The relationships of several genes suppressing plumage colour with body weight, food intake and feather loss of laying hens. Brit. Poult Sci., 20, 587-594.

Mérat P., Bordas A., L'Hospitalier R., Protais J., Bougon M., 1983. Etude des particularités de la poule Fayoumi. III. Ponte, caractéristiques des œufs, efficacité alimentaire et paramètres physiologiques de poules Fayoumi, Rhode-Island et F1 en batteries. Genet. Sel. Evol., 15, 147-166.

Meuret M., 1997. Préhensibilité des aliments chez les petits ruminants sur parcours en landes et sous-bois. INRA Prod. Anim. 10, 391-401.

Michalet-Doreau B., Martin C., Doreau M. 1997. Optimisation de la digestion des parois végétales dans le rumen : quantification des interactions digestives. Renc. Rech. Rum., 103-112.

Mignon-Grasteau S., Boissy A., Bouix J., Faure J.M., Fisher A.D., Hinch G.N., Jensen P., Le Neindre P., Mormède P., Prunet P., Vandeputte M., Beaumont C., 2005. Genetics of adaptation and domestication in livestock Livest. Anim. Sci., 93, 3-14.

Mirkena T., Duguma G, Haile A., Tibbo M., Okeyo A.M., Wurzinger M., Solkner J., 2010 Genetics of adaptation in domestic farm animals: A review. Livest. Sci., 132, 1-12.

Morand-Fehr P., Doreau M., 2001. Ingestion et digestion chez les ruminants soumis à un stress de chaleur. INRA Prod. Anim., 14, 15-27.

Moreno C.R., Gruner L., Scala A., Mura L., Schibler L., Amigues Y., Sechi T., Jacquiet P, François D., Sechi S., Roig A., Casu S., Barillet F., Brunel J.C., Bouix J., Carta A., Rupp R., 2006. QTL for resistance to internal parasites in two design based on natural and experimental conditions of infection. $8^{\text {th }}$ World Congr. Genet. Appl. Livest. Prod., Belo Horizonte, Brazil, 15-05.

Mount L.E., Monteith J.L., 1974. The concept of thermal neutrality heat loss from animals and man. Butterworths, London, UK, 425-439.

National Research Council, 1981. Effect of environment on nutrient requirements of domestic animals, Washington D.C., USA, 152p.

Naves M., 2003. Caractérisation et gestion d'une population bovine locale de la zone tropicale : le Bovin Créole de Guadeloupe. Thèse INA Paris Grignon,, Paris, France, 283p.

Naves M., Alexandre G., Leimbacher F., Mandonnet N., Menendez Buxadera A., 2000a. Les ruminants domestiques de la Caraïbe : le point sur les ressources génétiques et leur exploitation. INRA Prod. Anim. 14, 181-192.

Naves M., Leimbacher F., Alexandre G Mandonnet N.,2000b. Development of anima breeding strategies for the local breeds of ruminants in the French West Indies. workshop on developing breeding strategies for lower input animal production environments. Galal S., Boyazoglu J., Hammond K. (Eds). ICAR Technical Series, 3, 379-385.

Naves M., Menendez Buxadera A., Alexandre G., Mandonnet N., 2001. Etude comparative sur la méthodologie d'estimation des poids à âge type appliquée aux caprins Créole producteurs de viande. Rev. Elev. Méd. Vét. Pays Trop., 54, 81-87.

N'dri A.L., Mignon-Grasteau S., Sellier N., Beaumont C., Tixier-Boichard M., 2007. Interactions between the naked neck gene, sex, and fluctuating ambient temperature on heat tolerance, growth, body composition, meat quality, and sensory analysis of slow growing meat-type broilers. Livest. Sci., 110, 33-45.

Newman J.A., Penning P.D., Parsons A.J., Harvey A., Orr R.J., 1994. Fasting affects intake behaviour and diet preference of grazing sheep. Anim. Behav., 47, 185-193.

Nimbkar C., Ghalsasi P., Nimbkar B., 2000 Crossbreeding with the Boer goat to improve economic returns from smallholders'goats in India. $7^{\text {th }}$ Int. Conf. Goats, 15-21 May, Tours, France, 551-553.

Noblet J., Fortune H., Shi X.S., Dubois S. 1994. Prediction of net energy value of feeds for growing pigs. J. Anim. Sci., 72, 344-354.

Noblet J., Karege C., Dubois S., Van Milgen J., 1999. Metabolic utilization of energy and maintenance requirements in growing pigs: Effects of sex and genotype. J. Anim. Sci., 77, 1208-1216.

Noblet J., Le Bellego L., Van Milgen J. Dubois S.., 2001. Effect of reduced dietary protein level and fat addition on heat production and nitrogen and energy balance in growing pigs. Anim. Res., 50, 227-238.

Obexer-Ruff G., Sattler U., Martinez D., Maillard J.C., Chartier C., Saitbekova N., Glowatzki M.L., Gaillard C., 2003. Association studies using random and candidate microsatellite loci in two infectious goat diseases. Genet. Sel. Evol., 35, S113-S119.

O'Gorman G.M., Park S.D., Hill E.W., Meade K.G., Coussens P.M., Agaba M., Naessens J., Kemp S.J., MacHugh D.E., 2009. Transcriptional profiling of cattle infected with Trypanosoma congolense highlights gene expression signatures underlying trypanotolerance and trypanosusceptibility. BMC Genomics, 10, 207.

Over H.J., Jansen J., Von Olm P.W., 1992. Distribution and impact of helminth diseases of livestock in developing countries. Food and Agriculture Organisation of the United Nations Animal Production and Health, 96, 221p.

Parsons D.J., Armstrong A.C., Turnpenny J.R., Matthews A.M., Cooper K., Clark J.A., 2001. Integrated models of livestock systems for climate change studies. 1. Grazing systems. Global Change Biol., 7, 93-112.

Peacock C., 1996. Improving goat production in the tropics. A manual for development workers. Farm-Africa and Oxfam (Eds). Oxfam, UK, 387p.

Pegram R.G., Tatchell R.J., de Castro J.J., Chizyuka H.G.B., Creek M.J. McCosker P.J., Mora M.C., Nigarura G., 1993. Tick control: new concepts. World Anim. Rev., 74-75, 2-14.

Picard M., 1989. Heat effects on the laying hen. Protein nutrition and food intake. $5^{\text {th }}$ Eur. Symp. Poult. Nutr., 27-31 october. Male Hachamisha, Israel, 65-72. 
Picard M., Sauveur B., Fernadji F., Angulo I., Mongin P., 1993. Ajustements technicoéconomiques possibles de l'alimentation des volailles dans les pays chauds. INRA Prod. Anim., 6, 87-103.

Piestun Y., Shinder D., Ruzal M., Halevy O., Brake J., Yahav S., 2008. Thermal manipulations during broiler embryogenesis: effect on the acquisition of thermotolerance. Poult. Sci., 87, 1516-1525.

Piestun Y., Halevy O., Yahav S., 2009. Thermal manipulations of broiler embryos. The effect on thermoregulation and development during embryogenesis. Poult. Sci., 88 , 2677-2688.

Piper E.K., Jackson L.A., Bagnall N.H., Kongsuwan K.K., Lew A.E., Jonsson N.N., 2008. Gene expression in the skin of Bos taurus and Bos indicus cattle infested with the cattle tick, Rhipicephalus (Boophilus) microplus. Vet. Immunol. Immunopathol., 126, 110-119.

Piper E.K., Jonsson N.N., Gondro C., LewTabor A.E., Moolhuijzen P., Vance M.E., Jackson L.A., 2009. Immunological profiles of Bos taurus and Bos indicus cattle infested with the cattle tick, Rhipicephalus (Boophilus) microplus. Clin. Vaccine Immunol., 16, 1074-1086.

Poivey J.P., 1987. Development of breeding methods in the tropics with limited availability of in-the-field recording systems. World Rev. Anim. Prod., 23, 83-92.

Provenza F.D., 2008. What does it mean to be locally adapted and who cares anyway? J. Anim. Sci., 86 (E-Suppl.), E271-E284.

Putney D.J., Mullins S., Thatcher W.W., Drost M., Gross T.S., 1989. Embryonic development in superovulated dairy cattle exposed to elevated ambient temperatures between the onset of estrus and insemination. Anim. Rep. Sci., 19, 37-51.

Quiniou N., Massabie P., Granier R., 2000a. Diurnally variation of ambient temperature around 24 or $28^{\circ} \mathrm{C}$ : Influence on performance and feeding behavior of growing pigs. Proc. $1^{\text {st }}$ Int. Conf. Swine Housing, Des Moines, Iowa, USA, 332-339.

Quiniou N., Renaudeau D., Collin A., Noblet J., 2000b. Effets de l'exposition au chaud sur les caractéristiques de la prise alimentaire du porc à différents stades physiologiques. INRA Prod. Anim. 13, 233-245.

Ravagnolo O., Misztal I., Hoogenboom G., 2000. Genetic component of heat stress in dairy cattle, development of heat index function. J. Dairy Sci., 83, 2120-2125.

Ramsay K., Swart D., Olivier B., Hallowell G., 2000. An evaluation of the breeding strategies used in the development of the Dorper sheep and the improved Boer goat of South Africa. Workshop on developing breeding strategies for lower input animal production environments. Galal S., Boyazoglu J., Hammond K. (Eds). ICAR Technical Series, 3, 339-346.

Renaudeau D., Gourdine J.L., 2010. A metaanalysis of the effects of high ambient temperature on growing-finishing pigs performance. J. Anim. Sci., 88 (Suppl 2), 127.

Renaudeau D., Gourdine J.L., Quiniou N., Noblet J., 2005. Feeding behaviour of lactationsows in hot conditions. Pig News Inf., 26, $17 \mathrm{~N}-22 \mathrm{~N}$.

Renaudeau D., Giorgi M., Silou F., Weisbecker J.L., 2006. Effect of breed (lean or fat pigs) and sex on performance and feeding behaviour of group housed growing pigs in a tropical climate. Asian-Australasian J. Anim. Sci., 19, 593-601.

Renaudeau D., Gourdine J.L., Silva B.A.N., Noblet J., 2008. Nutritional routes to attenuate heat stress in pigs. In: Livestock and global climate change. Hammamet, Tunisia, 134-138.

Renaudeau D., Anaïs C., Tel L., Gourdine J.L., 2010. The effect of temperature level on thermal acclimation in growing pigs estimated using a non-linear function. J. Anim. Sci., 88, 3715-3724.

Rinaldo D., Marival P., Feuillet D., Calif B., 1998. Effects of tropical climate on energy balance in growing pigs. Proc. $8^{\text {th }}$ World Conf. Anim. Prod., Séoul, 154-155.

Robelin J., Agabriel J., Malterre C., Bonnemaire J., 1990. Changes in body composition of mature dry cows of Holstein, Limousin and Charolais breeds during fattening. I. Skeleton, muscles, fatty tissues and offal. Livest. Prod. Sci., 25, 199-215.

Rutagwenda T., Lechner-Doll N., Kaske M., Engelhardt W.V., Schultka W., Schwartz H.J., 1989. Adaptation strategies of camels on a thornbush savannah pasture, comparison with other domestic animals. Opt. Méd., 2, 69-73.

Salas M., Biessy G., Magne E., 1990. Effet du mode de conduite au pâturage et de la complémentation sur le comportement alimentaire des bovins en Guadeloupe. Rev Elev. Méd. Vét. Pays Trop., 43, 381-386.

Sandercock D.A., Hunter R.R., Mitchell M.A., Hocking P.M., 2006. Thermoregulatory capacity and muscle membrane integrity are compromised in broilers compared with layers at the same age or body weight. Brit. Poult. Sci., 47, 322-329.

Sangster N.C., 1999. Anthelmintic resistance: past, present and future. Int. J. Parasitol., 29, 115-124.

Sauvant D., 1994. Modeling homeostatic and homeorhetic regulations in lactating animal. Livest. Prod. Sci., 39, 105-113.

Schou T.W., Permin A., Juul-Madsen H.R., Sorensen P., Labouriau R, Nguyen T.L.H., Fink M., Pham S.L., 2007. Gastrointestinal helminths in indigenous and exotic chickens in Vietnam: association of the intensity of infection with the Major Histocompatibility Complex. Parasitology, 134, 561-573.

Siebert B.D., Macfarlane W.V., 1971. Water turnover and renal function of dromedaries in the desert. Physiol. Zool., 44, 225-240.

Silanikove N., 1994. The struggle to maintain hydration and osmoregulation in animals experiencing severe dehydration and rapid rehydration: the story of ruminants. Exp. Physiol., 79, 281-300.

Silanikove N., 2000. The physiological basis of adaptation in goats to harsh environments. Small Rum. Res., 35, 181-193.

Silanikove N., Tagari H., Shkolnik A., 1993. Comparison of rate of passage, fermentation rate and efficiency of digestion of high fiber diet in desert Bedouin goats compared to Swiss Saanen Goats. Small Rum. Res., 12, 45-60.

Silva B.A.N., Oliveira R.F.M., Donzele J.L., Fernandes H.C., Lima A.L., Renaudeau D., Noblet J., 2009. Effect of floor cooling and dietary amino acids content on performance and behaviour of lactating primiparous sows during summer. Livest. Sci., 120, 25-34.

Star L., Ellen E.D., Uitdehaag K., Brom F.W.A., 2008. A plea to implement robustness into a breeding goal: poultry as an example. J. Agric. Env. Ethics, 21, 109-125.

Tanor M.A., Leeson S., Summers J.D., 1984. Effect of heat stress and diet composition on performance of White-Leghorn hens. Poult. Sci., 63, 304-310.

Temim S., Chagneau A.M., Guillaumin S., Michel J., Peresson R., Geraert P.A., Tesseraud S., 1999. Effects of chronic heat exposure and protein intake on growth performance, nitrogen retention and muscle development in broiler chickens. Reprod. Nutr. Dev., 39, 145-156.

Temim S., Chagneau A.M., Peresson R., Tesseraud S., 2000. Chronic heat exposure alters protein turnover of three different skeletal muscles in finishing broiler chickens fed 20 or 25\% protein diets. J. Nutr., 130, 813-819.

Terefe G., Lacroux C., Andreoletti O., Grisez C., Prevot F., Bergeaud J.P., Penicaud J., Rouillon V., Gruner L., Brunel J.C., François D., Bouix J., Dorchies P., Jacquiet P., 2007. Immune response to Haemonchus contortus infection in susceptible (INRA 401) and resistant (Barbados Black Belly) breeds of lambs. Parasite Immunol., 29, 415-424.

Tesseraud S., Temim S., 1999. Modifications métaboliques chez le poulet de chair en climat chaud : conséquences nutritionnelles. INRA Prod. Anim., 12, 353-363.

Tichit M., Ingrand S., Moulin C.H., Cournut S., Lasseur J., Dedieu B., 2008. Capacités d'adaptation du troupeau : la diversité des trajectoires productives est-elle un atout ? In : L'élevage en mouvement. Flexibilité et adaptation des exploitations d'herbivores, Dedieu B., Chia E., Leclerc B., Moulin C.H., Tichit M. (Eds). Editions Quae, Paris, France, 119-134.

Tillard E., 2007. Approche globale des facteurs associés à l'infertilité et l'infécondité chez la vache laitière : importance relative des facteurs nutritionnels et des troubles sanitaires dans les élevages de l'ile de la Réunion. Doctorat d'Université, Université Montpellier II. Centre International d'études supérieures en sciences agronomiques, SupAgro Montpellier, France, $441 \mathrm{p}$.

Tisserand J.L., Hadjipanayiotou M., Gihad E.A., 1991. Digestion in goats. In: Goat nutrition. Morand-Fehr P. (Ed). PUDOC, Wageningen, Netherlands, 46-60.

Umar Faruk M., 2010. Evaluation of the impact of Loose-mix and Sequential feeding using locally available feed ingredients on performance in layer hen. Thèse de Doctorat de l'Université François Rabelais de Tours, France, $217 \mathrm{p}$.

Umar Faruk M., Lescoat P., Bouvarel I., Nys Y., Tukur H.M., 2010. Use of whole Millet (Pennisetum glaucum) and protein-mineral concentrate in poultry feeding is an efficient feed management method in Nigeria. XIII Eur. Poult. Conf., 24-27 August, Tours, France, 145.

Untalan P.M., Pruett J.H., Steelman C.D., 2007. Association of the bovine leukocyteantigen major histocompatibility complex class II DRB3*4401 allele with host resistance to the Lone Star tick, Amblyomma americanum. Vet. Parasitol., 145, 190-195.

Van Wyk J.A., 2001. Refugia - overlooked as perhaps the most potent factor concerning 
the development of anthelmintic resistance Onderstepoort J. Vet. Res., 68, 55-67.

Vercruysse J., Knox D.P., Schetters T.P.M., Willadsen P., 2004. Veterinary parasitic vaccines: pitfalls and future directions. Trends Parasitol., 20, 488-492.

Villalba J.J., Provenza F.D., Hall J.O. Lisonbee L.D., 2010. Selection of tannins by sheep in response to gastrointestinal nematode infection. J. Anim. Sci., 88, 2189-2198.

Wilson P.N., 1998. Adaptation of livestock to tropical environments. In: Agriculture in the Tropics, Webster C.C., Wilson P.N. (Eds). $3^{\text {rd }}$ Edition, Blackwell Science Ltd, Oxford, UK, 371-390.

Wolfenson D., 1986. The effect of acclimatization on blood flow and its distribution in normo-thermic and hyperthermic domestic fowl. Comp. Biochem. Physiol. A Comp Physiol., 85, 739-742.

Wolfenson D., Berman A., Yael F., Frei F, Snapir N., 1978. Measurement of blood flow distribution by radioactive microspheres in the laying hen (Gallus domesticus). Comp. Biochem. Physiol., 61, 549-554.

Xin H., 1999. Assessing swine thermal comfort by image analysis of postural behaviors. J Anim. Sci., 77, 1-9.

Yagil R., 1985. The desert camel: comparative physiological adaptation. Comparative animal nutrition. Karger, Basel, Allemagne, $164 \mathrm{p}$.

Yahav S., McMurtry J.P., 2001. Thermotolerance acquisition in broiler chickens by temperature conditioning early in life, the effect of timing and ambient temperature. Poult. Sci. $80,1662-1666$

Yahav S., Collin A., Shinder D., Picard M. 2004a. Thermal manipulations during broiler chick embryogenesis: effects of timing and temperature. Poult. Sci., 83, 19591963
Yahav S., Straschnow A., Luger D., Shinder D., Tanny J., Cohen S., 2004b. Ventilation, sensible heat loss, broiler energy, and water balance under harsh environmental conditions. Poult. Sci., 83, 253-258.

Yossifoff M., Kisliouk T., Meiri N., 2008. Dynamic changes in DNA methylation during thermal control establishment affect CREB binding to the brain-derived neurotrophic factor promoter. Eur. J. Neurosci., 28, 2267-2277.

Zerjal T., Gourichon D., Rivet B., Bordas A., 2010. The effect of the Frizzle $(F)$ gene on egg production traits under standard and high ambient temperature. $9^{\text {th }}$ World Congr. Genet. Appl. Livest. Prod., August 1-6, Leipzig, Germany, PP3-04

Zumbach B., Misztal I., Tsuruta S., Sanchez J. P., Azain M., Herring W., Holl J., Long T., Culbertson M., 2008. Genetic components of heat stress in finishing pigs: Parameter estimation. J. Anim. Sci., 86, 2076-2081

\section{Résumé}

En zones difficiles, la pérennité des systèmes d'élevage repose sur la capacité des animaux à survivre, se reproduire et maintenir un niveau de production en situation de fortes contraintes. Les principales contraintes auxquelles les animaux doivent faire face en régions chaudes, sont le climat (température et humidité), la sous-nutrition et les pathologies. Chez les monogastriques comme chez les ruminants, les caractéristiques anatomiques et le comportement alimentaire constituent les principaux facteurs de régulation des échanges thermiques. L'élément clé de l'adaptation comportementale des ruminants à la sous-alimentation est leur capacité à choisir leur alimentation. L'adaptation physiologique porte sur la réduction du métabolisme basal, l'efficience digestive, la valorisation de fourrages grossiers, la mobilisation des réserves corporelles, le recyclage des nutriments et la valorisation efficiente de l'eau. Les travaux les plus significatifs sur la résistance génétique aux maladies portent sur la trypanotolérance, la résistance aux maladies transmises par les tiques et les strongyloses gastro-intestinales. Dans l'élevage moderne, la gestion de ces contraintes environnementales doit se concevoir de façon intégrée. Différentes techniques d'alimentation, de prophylaxie, de gestion d'ambiance des bâtiments d'élevage doivent être combinées pour garantir durablement la pérennité des systèmes d'élevage. Cependant, l'efficacité de cette approche intégrée repose également sur le potentiel adaptatif des animaux pour répondre aux pratiques mises en ouvre. Le développement des productions animales en régions chaudes ne pourra être garanti sans l'utilisation de l'adaptation naturelle des populations animales ou pour le moins, sans inclure les caractères d'adaptation dans les objectifs de sélection des races locales ou spécialisées.

\section{Abstract}

\section{Adaptation of livestock to the constraints of tropical regions}

The question of adaptation of animals to the tropical environment has become a major challenge for the livestock sector and the scientific community. In harsh areas, the sustainability of farming systems is based on the ability of animals to survive, reproduce and maintain productivity under climatic, food or health constraints. In monogastrics and ruminants, the anatomical characteristics and feeding behavior are key factors regulating heat exchanges (small-size, decrease in subcutaneous fat mass, reduction in feed intake and physical activity). Level of basal metabolic rate, digestive efficiency, ability to utilize lower quality feeds, body reserves mobilization, nutrient recycling and water use efficiency are the main physiological traits of adaptation to underfeeding in ruminants. The most significant works on disease genetic resistance relate to trypanotolerance in African livestock, resistance to ticks or tick-borne diseases like heartwater and resistance to gastrointestinal strongyles. In modern farming systems, management of these environmental constraints must be considered in an integrated framework. Various feeding, environment and health management practices must be combined to reduce risk and maximize productivity. However, sustainable development of livestock production in tropical areas cannot be guaranteed without using the adaptation traits of native animal populations or at least without including adaptation traits in selection program for local and exotic breeds.

MANDONNET N., TILLARD E., FAYE B., COLLIN A., GOURDINE J.-L., NAVES M., BASTIANELLI D., TIXIER-BOICHARD M., RENAUDEAU D., 2011. Adaptation des animaux d'élevage aux multiples contraintes des régions chaudes. In : Numéro spécial, Elevage en régions chaudes. Coulon J.B., Lecomte P., Boval M., Perez J.M. (Eds). INRA Prod. Anim., 24, 41-64. 